NASA

Technical Memorandum 107114

AIAA-96-0243
Army Research Laboratory

Technical Report ARL-TR-925

\title{
Macroscopic Balance Model for Wave Rotors
}

Gerard E. Welch

Vehicle Propulsion Directorate

U.S. Army Research Laboratory

Lewis Research Center

Cleveland, Ohio

Prepared for the

34th Aerospace Sciences Meeting and Exhibit

sponsored by the American Institute of Aeronautics and Astronautics

Reno, Nevada, January 15-18, 1996

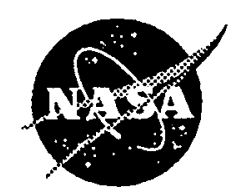

National Aeronautics and

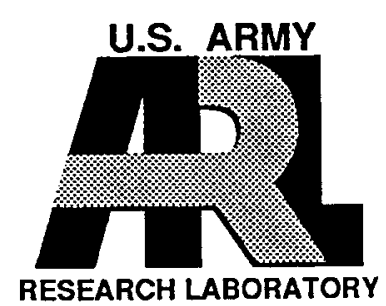




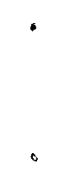




\title{
Macroscopic Balance Model for Wave Rotors
}

\author{
Gerard E. Welch* \\ U.S. Army Research Laboratory \\ NASA Lewis Research Center \\ 21000 Brookpark Road, M/S 77-6 \\ Cleveland, $\mathrm{OH} 44135$
}

\begin{abstract}
A mathematical model for multi-port wave rotors is described. The wave processes that effect energy exchange within the rotor passage are modeled using one-dimensional gas dynamics. Macroscopic mass and energy balances relate volume-averaged thermodynamic properties in the rotor passage control volume to the mass, momentum, and energy fluxes at the ports. Loss models account for entropy production in boundary layers and in separating flows caused by blade-blockage, incidence, and gradual opening and closing of rotor passages. The mathematical model provides a basis for predicting design-point wave rotor performance, port timing, and machine size. Model predictions are evaluated through comparisons with CFD calculations and three-port wave rotor experimental data. A fourport wave rotor design example is provided to demonstrate model applicability. The modeling approach is amenable to wave rotor optimization studies and rapid assessment of the trade-offs associated with integrating wave rotors into gas turbine engine systems.
\end{abstract}

\section{Introduction}

The wave rotor is an internal flow machine designed to efficiently exchange energy between gas streams of differing energy density. The energy exchange is accomplished by compression and expansion waves which propagate longitudinally along shrouded rotor passages (see Fig. 1). The gas dynamic waves are initiated as the passages open and close to the steadyflow in the inlet and exhaust ports in a timed sequence dictated by the azimuthal location and extent of the ports (stators) and the rotor speed. At an inlet port, low pressure gas within a rotor passage is exposed to the high pressure gas in the inlet port and a compression wave moves into the passage and compresses the onboard gas, allowing the port flow to enter the passage. At an outlet port, the typically higher pressure passage gas is exposed to the low pressure port flow and an expansion wave moves into the passage, reduces the

*Aerospace Engineer, Vehicle Propulsion Directorate; member AIAA This paper is declared a work of the U.S. Government and is not subject to copyright protection in the United States. passage pressure, and exhausts the on-board gas to the outlet port. The charging and exhausting processes are exploited in the wave rotor to effect different gas cycles. These include three-port divider cycles, ${ }^{1,2}$ various multiport (e.g., two-port, ${ }^{3}$ four-port, ${ }^{4,5}$ and nine-port ${ }^{6}$ ) cycles used to top gas turbine engines, and wave engines which produce net shaft power. ${ }^{7}$ The interesting history of the wave rotor and its applications is documented elsewhere. ${ }^{8-11}$

NASA Lewis Research Center is currently evaluating and characterizing the performance of wave rotors with an aim toward applying wave rotor technology to increase the performance of gas turbine engines. ${ }^{12} \mathrm{~A}$ strong component of this effort is concentrated on developing computational fluid dynamic (CFD) tools ${ }^{13-15}$ to simulate accurately wave rotor flow dynamics. The purpose of this paper is to describe a mathematical model that provides accurate design-point wave rotor performance. The model is suitable for preliminary port timing and duct angle estimates. The modeling approach provides a tool for wave rotor size optimization and wave rotor/gas turbine engine integration assessment studies.

The paper is arranged as follows: The mathematical model is first described. Model predictions are then compared with CFD results and three-port experimental data. Finally, the model is used to design a four-port wave rotor for a small turboshaft engine topping cycle as a demonstration of model applicability.

\section{Mathematical Model}

\section{Overview}

The wave rotor model has three principle elements: 1.) macroscopic balances that enforce global mass and energy conservation in a wave rotor passage as it rotates between strategically defined end-states within a prescribed wave rotor cycle; 2 .) one-dimensional gas dynamic wave calculations which establish the port timing and the mass, momentum, and energy fluxes at the passage ends; and 3.) entropy production models for principle wave rotor loss mechanisms. The gas is 
assumed to be at rest in the rotor frame of reference at the defined end-states; the gas in these states may be non-uniform and discontinuous (e.g., contain contact discontinuities). Gas particles are assumed to travel along paths of constant radius. The working fluid is treated as a perfect gas with a constant ratio of specific heats $(\gamma)$. The rotor passage walls are treated as adiabatic surfaces and volumetric heat generation (e.g., by combustion) is zero.

The macroscopic balances are developed in the next section. The gas dynamic wave processes and timing, and the entropy production mechanisms inherent to the wave cycle are then described. Finally, entropy production models for the other important wave rotor loss mechanisms are presented.

\section{Macroscopic Balances}

The conservation of mass for a generalized control volume, $\mathrm{V}$, requires that

$$
\frac{d}{d t} \int_{V(t)} \rho d V=-\int_{A(t)} \rho\left(\underline{u}-\underline{u}_{s}\right) \cdot \underline{n} d A
$$

where $\rho$ is the local density, $\underline{u}$ is the local fluid velocity, $\underline{u}_{s}$ is the local control surface velocity, and $A$ is the control surface area with unit normal, $\underline{n}$. The conservation of energy requires that

$$
\frac{d}{d t} \int_{V(t)} \rho e_{t} d V=-\int_{A(t)} \rho h_{t}\left(\underline{u}^{-}-\underline{u}_{s}\right) \cdot \underline{n} d A-\int_{A(t)} p \underline{u} \cdot \underline{n} d A
$$

where $e_{t} \equiv e+\frac{1}{2} \underline{u} \cdot \underline{u}$ is the specific total energy, $h \equiv e+p / \rho$ is specific total enthalpy, $e$ and $p$ are the specific internal energy and static pressure, respectively, and $\int_{p} \underline{u}_{s} \cdot \boldsymbol{n} d A$ is the boundary work rate. Using conservation of angular momentum

$$
\begin{aligned}
\frac{d}{d t} \int_{V(t)} \rho u_{\theta} r \Omega d V= & -\int_{A(t)} \rho u_{\theta} r \Omega\left(\underline{u}_{-}-\underline{u}_{s}\right) \cdot \underline{n} d A \\
& -\int_{A(t)} p r \Omega \underline{e} \cdot \underline{n} d A
\end{aligned}
$$

where $\Omega$ is a constant rotor angular speed, $r$ is radius, and $u_{\theta}$ is the local tangential velocity component, allows Eqn. 2 to be rewritten as

$$
\begin{aligned}
\frac{d}{d t} \int_{V(t)} \rho e_{t}^{\prime} d V= & -\int_{A(t)} \rho h_{t}^{\prime}\left(\underline{u}_{t}-\underline{u}_{s}\right) \cdot \underline{n} d V \\
& -\int_{A(t)} p\left(\underline{u}_{s}-r \Omega \underline{e}_{\theta}\right) \cdot \underline{n} d A
\end{aligned}
$$

where $e_{t}^{\prime} \equiv e+\frac{1}{2}\left(\underline{w} \cdot \underline{w}-(r \Omega)^{2}\right), \quad h_{t}^{\prime} \equiv e_{t}^{\prime}+p / \rho$, and $\underline{w} \equiv u-r \Omega e$. The energy $e^{\prime}$ is by definition uninfluenced $\bar{\theta}^{\theta}$ by shaft work rate (in Eqn. 3).

Eqn. 4 elicits an interesting description of the wave rotor energy exchange process: Consider two adjacent control volumes within a rotor passage that share a boundary that moves with some relative velocity component $(w)$ normal to the passage cross-sectional area $(A)$, across which pressure $(p)$ is continuous (e.g., a contact discontinuity or particle path). Eqn. 4 shows that the rate at which relative total energy is added to one of the control volumes by work at the shared boundary $\left(\int p w d A\right)$ is by definition equal to the rate at which boundary work is extracted $\left(-\int p w d A\right)$ from the adjacent control volume; i.e., the energy exchange between the two control volumes is effected by this boundary work rate term in the macroscopic balance approach. This description of energy exchange is conceptually useful because it does not dependent on the details of the gas dynamic waves instantaneously captured within either of the control volumes. Of course, it is the wave processes that dictate the pressure and velocity fields that define the integrand of the boundary work rate term. Typically, the boundary work integral cannot be solved analytically without first solving for the time-dependent flow field using a method-of-characteristic or CFD approach; to do this would defeat the purpose of the macroscopic balance approach. Attention is therefore restricted to the control volume defined by the full rotor passage. The boundary work rate term of Eqn. 4 is thus zero and the rate of change of the relative total energy within the rotor passage depends only on the net flux of rothalpy through the passage ends.

Eqns. 1 and 4 can be integrated between two times 1 and 2 on the rotor-or because the rotor speed is a constant relating time and azimuthal position $(d \theta=\Omega d t)$, between the two arbitrary azimuthal positions - to give

$$
\bar{\rho}_{2}=\bar{\rho}_{1}+\frac{1}{V_{P}}\left[\left(\int_{A_{p}} \int_{1}^{2} \rho u d t d A\right)_{\text {in }}-\left(\int_{A_{P}} \int_{1}^{2} \rho u d t d A\right)_{\text {out }}\right](5)
$$

and

$$
\bar{p}_{2}=\bar{p}_{1}+\frac{1}{V_{P}}\left[\left(\int_{A_{P} 1}^{2} \rho u a_{t, r}^{2} d t d A\right)_{\text {in }}-\left(\int_{A_{P} 1}^{2} \int_{1} \rho u a_{t, r}^{2} d t d A\right)_{o u t}\right]
$$


provided that the gas at States 1 and 2 is essentially at rest $(\underline{w} \cdot \underline{w} \propto 0)$ in the rotor frame of reference. The squared-speed of sound, $a_{t, r}^{2}=(\gamma-1)\left(h_{t}^{\prime}+(r \Omega)^{2} / 2\right)$, is based on the local relative total temperature, $\bar{\rho}$ is the volume-averaged density and $\bar{p}$ is volume-averaged pressure, $u\left(=w_{x}\right)$ is the through-flow component of velocity, $A_{P}$ is the passage cross-sectional area at the port/rotor interface, $V_{P}$ is the rotor passage volume, and $t$ is time. Eqn. 6 provides an expression for the average static pressure (or relative total pressure) in States 1 and 2. It is convenient to non-dimensionalize by reference state properties ( $\rho_{V}$ and $\left.a_{V}\right)$. The non-dimensional density and speed of sound in the reference state are both defined as unity and, by the equation-of-state $\left(\gamma p=\rho a^{2}\right)$, the static and (relative stagnation) nondimensional pressure is $1 / \gamma$. Lengths are normalized by the rotor length, $L_{P}$, and thus time is conveniently normalized by the time for a sound wave to traverse the rotor in the reference state, $t_{V}=L_{P} l a_{V}$.

In addition to relating states at strategic times in the wave cycle, Eqns. 5 and 6 enforce global mass and energy conservation. For example, because the unsteady flow in a wave rotor passage is periodic in time then, if State 2 (above) is chosen to be coincident with State 1 (one rotor revolution later in time), it is seen that Eqn. 5 simply expresses that the mass entering the wave rotor in one revolution equals the mass leaving the wave rotor in that revolution; similarly, Eqn. 6 requires that the relative total energy be conserved in this same time. An analogous application of Eqn. 3 provides an expression for rotor shaft work.

\section{Wave Processes and Timing}

The port timing-i.e. the leading and trailing azimuthal position of the ducts-is set by the specified wave position-time ( $x-t)$ diagram and the speed of the gas dynamic waves that effect the energy transfer in the wave rotor passages. Isentropic compression and expansion waves are treated using the invariance of Riemann variables along their characteristics and across waves of the opposite gender (cf. Ref 16). The Rankine-Hugoniot relations are used to calculate shock speeds, compression work, and inherent entropy production. Except where noted, wave speeds are calculated using one-dimensional gas dynamics in which blade-to-blade and radial variations in speed are neglected; further, the predicted wave speeds are not influenced by local flow losses (e.g., boundary layer attenuation of shock speed) or multi-dimensional effects (e.g., the gradual, rather than instantaneous, opening and closing of passages). Global loss mechanisms do however influence timing through their influence on the average entropy of the control volume. The modeling presented in this section includes entropy production inherent in shock waves and that introduced in mixing non-uniform velocity port flows. Other wave rotor loss mechanisms are addressed in later discussion.

\section{Low pressure exhaust port}

It is a good assumption (later enforced by design) in the wave rotors of this work that the gas in the (reference) passage about to open to the exhaust port is uniform and at rest in the rotor frame of reference. Figure 2a shows a position-time diagram of such a rotor passage exhausting its on-board contents to a port of uniform, constant static pressure. The exhaust process is characterized by the fan pressure ratio, $\epsilon$, or the ratio of uniform static back pressure $\left(p_{e}\right)$ in the low pressure port and the on-board pressure, $p_{V}$. The principle fan initiated at $t=0$ reflects off the wall $(x=0)$ and the head (leading end) of the fan arrives back at the exhaust port at $t=t_{a}$. In the uniform region $0 \leq t \leq t$, the passage gas is discharged with uniform axial velocity given by

$$
u\left(0 \leq t \leq t_{a}\right)=u_{e}=\frac{2}{\gamma-1}\left(1-\epsilon^{1 /(2 \Gamma)} e^{\Delta s_{f} / R}\right)
$$

where $\Delta s_{f} / R$ is the mass-averaged entropy produced in the boundary layers of the gas discharged in the uniform region-zero for the present discussion, but see later discussion in section on boundary layer loss $-R$ is the gas constant, and $\Gamma=\gamma /(\gamma-1)$. The reflected fan reduces the exhaust port discharge velocity and establishes the non-uniform velocity region $\left(t_{a} \leq t \leq t_{b}\right)$ noted in Fig 2a. The exhaust port is closed (at time $t_{b}$ ) when the velocity in the exhaust port reaches zero which corresponds to the time when the mid-characteristic of the principle expansion fan (shown in Fig. 2a) arrives back at the exhaust port. Although the time at which the head of the expansion fan reaches the exhaust port $\left(t_{a}\right)$ can be obtained analytically (and explicitly), recourse to the method-of-characteristics (e.g., see Ref. 16) provides the port closing time, $t_{b}$. The coarse MOC calculation involves the head, tail, and mid-characteristic of the expansion fan. The characteristics are treated as straight lines connecting the nine nodes identified in Fig. 2a. The slope (propagation velocity) of each line is based on the average of the wave speeds at the two connected nodes. The velocity in the non-uniform region between the reflected head and mid-characteristic of the fan $\left(t \leq t \leq t_{b}\right)$ is well approximated by 


$$
u\left(t_{a} \leq t \leq t_{b}\right)=\frac{u_{e} t_{a}}{\left(t_{b}-t_{a}\right)}\left\{\frac{t_{b}}{t}-1\right\}
$$

which is derived assuming that the reflected fan in this region can be represented by a centered fan which reduces the discharge velocity from $u_{e}$ at $t_{a}$ to zero at $t_{b}$. Given the times $t_{a}$ and $t_{b}$, and assuming isentropic expansion (i.e., neglecting entropy production internal to the passages for the moment), allows the mass, momentum, and total energy discharged per unit area (see time integrals of Eqns 5 and 6) to be obtained using

$$
\begin{aligned}
& m_{\text {out }}=\int_{0}^{t_{b}} \rho u d t=\rho_{e} u_{e} \frac{t_{a} t_{b}}{\left(t_{b}-t_{a}\right)} \ln \left(t_{b} / t_{a}\right) \\
& \int_{0}^{t_{b}}\left(\rho u^{2}+p\right) d t=\rho_{e} u_{e}^{2} t_{a} f\left(t_{b} / t_{a}\right)+p_{e} t_{b}
\end{aligned}
$$

$$
\begin{aligned}
& \text { and } \\
& \qquad \int_{0}^{t_{b}} \rho u a_{t, r}^{2} d t=m_{o u t}\left(a_{e}^{2}+\frac{\gamma-1}{2} u_{e}^{2} g\left(t_{b} / t_{a}\right)\right)
\end{aligned}
$$

where $p_{e}=\epsilon^{1 / \gamma}, a_{e}^{2}=\epsilon$, given $p_{e}=\epsilon / \gamma$, and where

$$
f(\zeta) \equiv 1+\frac{\zeta}{(\zeta-1)^{2}}\left(\zeta-\zeta^{-1}-2 \ln \zeta\right)
$$

and

$$
g(\zeta) \equiv \frac{1-\zeta^{-1}+(\zeta-1)^{-2}\left[\frac{3}{2}+\frac{1}{2} \zeta^{2}-3 \zeta+\zeta^{-1}+3 \ln \zeta\right]}{\ln \zeta} .
$$

Mixed-out exhaust port properties are calculated by solving for the uniform flow field that in time $t_{b}$ discharges the mass, momentum, and energy calculated using Eqns. 7-13. This standard analytical procedure (e.g., see Ref. 17) for constant area mixing is not reproduced here, but provides explicit expressions for the mixed-out flow variables, including the mixed-out relative total pressure $\left(\left(p_{t, r}\right)_{\text {out }}\right)$ and temperature $\left(\left(a_{t, r}^{2}\right)_{\text {out }}\right)$. Table 1 compares results of the present work with a method-of-characteristics (MOC) calculation, ${ }^{16}$ a one-dimensional CFD calculation, ${ }^{13}$ and analytical values for an example pressure ratio of 0.353 (chosen in Ref. 16). Note that although the fan expansion process is assumed isentropic here, the entropy production implied in the mixing to a uniform exhaust port flow (see more detailed discussion of non-uniform port mixing loss presented later) is reflected by the $96.5 \%$ polytropic efficiency $\left(\eta_{\text {out }}=\ln \left(\left(a_{t, r}^{2}\right)_{\text {out }}^{\Gamma}\right) / \ln \left(\gamma\left(p_{t, r}\right)_{\text {out }}\right)\right)$ of the isentropic expansion and port mixing process.

The static pressure and density in State $Q$ of Figs. 2a and $2 \mathrm{~b}$ can be calculated using Eqns. 7-13 along with the mass and energy balances (Eqns. 5 and 6). Note that although the principle fan is here assumed isentropic, the static pressure and temperature in State $Q$ is not related isentropically to the static conditions in the reference State V; rather, the entropy produced by the coalescing compression wave reflected off the nonuniform region of the low pressure port and entropy production implied in establishing a quiescent State $Q$ is given by

$$
\frac{\Delta s_{v q}}{R}=\ln \left(\frac{\left\{1-\gamma m_{\text {out }}\left(a_{t, r}^{2}\right)_{\text {out }}\right\}^{\Gamma-1}}{\left\{1-m_{\text {out }}\right\}^{\Gamma}}\right) .
$$

\section{Low Pressure Inlet Port}

Efficient two-port machines with combustion internal to the rotor (cf. Ref. 3) and four-port pressure exchangers (e.g., Refs. 18 and 19) proposed to enhance gas turbine engine performance use the low pressure inlet and outlet port arrangement of Fig. 3 to provide pressure gain. In the pressure exchanger, the straightbladed rotor produces zero net power by design and the mixed-out total pressure of the low pressure exhaust port $\left(\left(p_{t}\right)_{\text {out }}\right)$ is higher than the total pressure of inlet port flow $\left(\left(p_{t}\right)_{\text {in }}\right)$. The ratio of inlet and outlet port total pressures is a function of the ratio of total temperatures in these ports, the fan pressure ratio $(\epsilon)$, the ratio of specific heats, the rotor Mach number, and the loss levels.

Figure $3 \mathrm{a}$ indicates that the principle expansion fan reduces the pressure at the left $(x=0)$ end of the machine. The low pressure inlet port is opened-or more correctly the passage opens to the port-soon after the pressure at the inlet side of the rotor is lower than the relative total pressure of the inlet port, $\left(p_{t, r}\right)_{\text {in }}$. The 
Table 1. Comparison of non-dimensional times, mass discharge fraction, total temperature, total pressure, and exhaust process polytropic efficiency for unsteady discharge of compressed $(\gamma=1.4)$ air from an instantaneously opened rotor passage at pressure ratio, $\epsilon=0.353$ (after Rudinger ${ }^{16}$ ).

\begin{tabular}{|c|c|c|c|c|c|c||}
\hline & $\mathbf{t}_{\mathbf{a}}$ & $\mathbf{t}_{\mathrm{b}}$ & $\left(m_{\text {out }} / m_{V}\right)$ & $\left(\left(a_{t, \mathrm{r}}^{\mathbf{2}}\right)_{\text {out }} / a_{V}\right.$ & $\left(p_{t, r}\right)_{\text {out }} / p_{V}$ & $\eta_{\text {out }}$ \\
\hline \hline Present Model & $1.737^{\mathrm{a}}$ & 2.588 & $0.692^{\mathrm{b}}$ & $0.829^{\mathrm{c}}$ & $0.506^{\mathrm{d}}$ & $0.965^{\mathrm{c}}$ \\
\hline M O C $^{\mathbf{1 6}}$ & $\approx 1.77$ & $\approx 2.66$ & $\approx 0.72$ & -- & -- & - \\
\hline 1-D CFD & 1.724 & 2.600 & 0.692 & 0.829 & 0.505 & 0.961 \\
\hline Analytical & 1.7342 & -- & -- & -- & -- & -- \\
\hline
\end{tabular}

$t_{a}$ and $t_{b}$ are from three-wave MOC calculation.

brom Eqn. 9.

cfrom Eqn. 11.

mixed-out total pressure using Eqns. 7-14.

'polytropic efficiency, $\eta_{\text {out }} \equiv \Gamma \ln \left(\left(a_{t, r}^{2}\right)_{\text {out }} / a_{v}^{2}\right) / \ln \left(\left(p_{t, r_{\text {out }}}\right) / p_{v}\right)$.

inflow gas is subsequently compressed by the shock formed by the coalescing compression waves produced as the principle expansion wave reflects off the nonuniform portion of the low pressure exhaust port. State $\mathrm{Q}$, which in Figs. $2 \mathrm{a}$ and $2 \mathrm{~b}$ contains only the fraction of State V gas not discharged from the exhaust port, is here comprised of two states (as shown in Fig. 3): State C contains the compressed inlet gas and State D contains the un-discharged State V gas.

Imposing the macroscopic balances (Eqns. 5 and 6) on a passage moving from State $V$ to $Q$ (containing $C$ and D) provides the volume-averaged density $\left(\rho_{Q}\right)$ and the volume-averaged relative total (or static) pressure $\left(p_{Q}\right)$

$$
\frac{\rho_{Q}}{\rho_{V}}=1+\frac{m_{\text {out }}}{m_{V}}\left(\frac{m_{\text {in }}}{m_{\text {out }}}-1\right)
$$

and

$$
\frac{p_{Q}}{p_{V}}=1+\gamma \frac{\left(m a_{t, r}^{2}\right)_{\text {out }}}{\left(m a_{t, r}^{2}\right)_{V}}\left(\frac{\left(m a_{t, r}^{2}\right)_{\text {in }}}{\left(m a_{t, r}^{2}\right)_{\text {out }}}-1\right),
$$

respectively, where $m_{\text {out }} / m_{V}$ is the fraction of State V mass discharged to the low pressure port, and where typically the inflow and outflow masses are either equal or related (e.g., in a gas turbine engine application, by a coolant bleed fraction $\left.f_{b}=1-\left(m_{\text {out }} / m_{\text {in }}\right)\right)$. The relative temperature ratio is implicitly specified by specifying the total temperature ratio, fan pressure ratio, and a rotor Mach number (e.g., $M_{\mathrm{a}, \mathrm{V}} \equiv \Omega r$ or $\left.M_{Q, i n} \equiv \Omega r /\left(a_{t}\right)_{\text {in }}\right)$, and the inflow and outflow mass averaged-relative tangential velocity $\left(\bar{w}_{0}\right)$; the port angles are ideally set so that at the design point $\bar{w}_{\theta} / \bar{u}=\tan \beta$, where $\beta$ is the blade angle (e.g., zero for a pressure exchanger) and $\bar{u}$ is the mass-averaged axial velocity. Imposing Eqn. 4 on the control mass in State D would relate States D and V if the boundary work integral in Eqn. 4 could be solved. As mentioned earlier, this is unfortunately not the case in the present work; therefore, the mass-averaged temperature in State $\mathrm{D}$ is related to that in State $\mathrm{V}$ by the model expansion process

$$
\frac{a_{D}^{2}}{a_{V}^{2}}=\left(\frac{p_{Q}}{p_{V}}\right)^{1 / \Gamma} e^{\Delta s_{b l} / R} e^{\Delta s_{e t} / R}
$$

where $\Delta s_{b l} / R$ is the mass-averaged boundary layer entropy production during the exhaust port discharge process (see later discussion on boundary layer entropy production) and $\Delta s_{c s} / R$ is the entropy produced as the undischarged fraction of State $\mathrm{V}$ gas is compressed by the coalescing waves reflected from the non-uniform region of the exhaust port; this entropy production is 
estimated using

$$
\frac{\Delta s_{c s}}{R}=C_{s} s_{s}\left(\left(a_{\text {out }} / a_{\text {in }}\right) M_{x, \text { in }}^{2}\right) / R
$$

where $S_{s}\left(M_{x}^{2}\right) / R$ is the entropy production in a shock with a relative inflow Mach number $M_{x}, a_{\text {in }}$ and $a_{\text {out }}$ are the (mixed-out) speeds of sound in the inlet and outlet ports, respectively, $M_{x, i n}$ is the Mach number of the inlet port flow relative to the shock wave traversing region $\mathrm{C}$, and $C_{s}$ is an empirical constant $(0.23)$ set by comparisons with 1-D CFD results (cf. Fig. 4). Given the temperature in State $\mathrm{D}$, and using the volumeaveraged static pressure of State $Q$ calculated earlier, the density of the fluid in State $D$ can be calculated. Knowing that the mass of fluid in State D is the undischarged fraction of the mass in reference State $V$, the (average) position of the contact separating States $C$ and $D$ can be calculated. Knowing that the mass in State $C$ equals $m_{\text {in }}$ and the average position of the interface between States $C$ and $D$, the average density in State $C$ is calculated. Using this density with the volumeaveraged pressure $p_{Q}$, the temperature in State $\mathrm{C}$ is known through the equation-of-state. The relative total temperature in the rotor inlet port is known in terms of the outflow total temperature and rotor Mach number and a specified relative velocity distribution; the ratio of the relative total temperatures across the coalesced shock can be calculated using the shock relations

$$
\frac{\left(a_{t, r}^{2}\right)_{c}}{\left(a_{t, r}^{2}\right)_{i n}}=\frac{1+\frac{\gamma-1}{2}\left(M_{x, i n}^{2}-M_{s}^{2}\right)}{1+\frac{\gamma-1}{2}\left(M_{x, i n}+M_{s}\right)^{2}}
$$

and

$$
M_{s}^{2}=\frac{2}{\gamma-1}\left\{1+\frac{\gamma-1}{2} M_{x, i n}^{2}-a_{c}^{2} / a_{i n}^{2}\right\}
$$

where

$$
a_{c}^{2} / a_{i n}^{2}=\left[1+\frac{2 \gamma}{\gamma+1}\left(M_{x, i n}^{2}-1\right)\right]\left[1-\frac{2}{\gamma+1}\left(1-1 / M_{x, \text { in }}^{2}\right)\right]
$$

and where the shock Mach number $M_{s}$ is negative (for port orientation shown in Fig. 3), and the $M_{x, \text { in }}$ is the (positive) Mach number of the inlet port flow relative to both the rotor and the coalesced shock wave. Having previously calculated the properties of State $C$, and now having obtained $M_{x, i n}$, the static and total properties and through-flow velocity in the inlet port are obtained. The mass entering the inlet port is related to the exhaust mass (i.e., is known); therefore, the total time that the inlet port is open $\left(t_{\text {in }}\right)$ can be calculated. The inlet port is closed when the coalesced shock reaches the inlet side of the rotor $(\mathrm{x}=0)$. This time $\left(t_{d}\right)$ is that for a sound wave to traverse State $D$, plus the time for the coalesced shock wave to traverse State $C$, plus the time that the exhaust port is open $\left(t_{b}\right)$; the inlet port, therefore, opens (at $t_{c}$ ) a time $t_{i n}$ earlier than the closing time, $t_{d}$.

Predictions of the ratio of the inlet and outlet port relative total pressures as a function of the inlet and outlet relative total temperatures and the principle fan expansion ratio $\left(\epsilon \equiv p_{e} / p_{V}\right)$ using the model of this work and a 1-D CFD code ${ }^{13}$ are compared in Fig. 4. Only shock and non-uniform port flow mixing losses are accounted for in these "ideal" inviscid calculations in which gradual opening and closing, blade blockage, and incidence losses are neglected; the loss models of the CFD code are similarly disabled. Having set the empirical constant $C_{s}$ (of Eqn. 18) at a constant value, the agreement between the analytical and CFD predictions for the inviscid flow with only shock and non-uniform port flow mixing losses is excellent.

The low pressure ports shown in Figs. 2 and 3 can be modeled independently from the high pressure ports because State $V$ is specified at the uniform, quiescent, reference conditions. It is interesting to note that, having required that the reference State $V$ be a uniform, zero-relative velocity state, the pressure ratio versus temperature ratio functions shown in Fig. 4 holds for any "ideal" cycle, using the low pressure port configuration of Fig. 3a, that effectively produces the uniform State V; i.e., it matters not whether State V is produced by a four-port wave rotor with either reverse or through-flow cycles (discussed in the next section), or by a wave rotor with combustion internal to the rotor (cf. Ref. 3), or by other envisaged multi-port cycles including wave engines with net shaft power output, the same relative total pressure ratio versus relative total temperature ratio holds in the "ideal" limit. The next section describes the model of the high pressure ports that establish State V in the present work.

\section{High Pressure Ports}

The gas inside the passage at State $Q$ experiences the gas dynamics indicated in the high pressure ports of Figs. $3 a$ and $3 b$. Two different approaches are considered: In the through-flow cycle approach of Fig. 3a the entire State $Q$ is discharged through the high pressure exhaust port on the same $\left(\mathrm{x}=L_{P}\right)$ end of the machine as the low pressure exhaust port; in the reverse- 
flow cycle of Fig. 3b, State $C$ is discharged from the exhaust port located on the same end $(x=0)$ of the machine as the low pressure inlet port.

Through-flow cycle. The passage which is initially at the static pressure in quiescent State $Q$ prior to opening to the high pressure inlet port is compressed by the principle shock wave driven by the inlet port flow. In reality, as the passage gradually opens $(t)$ to the port flow an expansion wave moves into the port, reducing the total pressure of the charging fluid, during the opening time. Compression waves, eventually steepening into a shock wave form as the passage opens. The shock wave compresses the on-board (State Q [or C]) fluid, allowing the port flow to enter the passage. In the case of the four-port cycle of Fig. 3a the principle shock first compresses the State $\mathrm{C}$ fluid which entered the rotor in the low pressure inlet port. As an incoming shock interacts with a contact-e.g., in the four-port, that between States C and D-a shock wave is transmitted and a either a shock wave or an expansion wave is reflected, depending on the shock temperature ratio and direction (i.e., hot-to-cold or cold-to-hot). As the transmitted shock reaches the exhaust port end of the rotor, the high pressure exhaust port is opened $\left(t_{g}\right)$ and a reflected shock (of different strength than transmitted shock) is reflected. The State C and D gases are recompressed by the reflected wave. The twice compressed States C and D gases now exit the rotor at the static back pressure dictated by the expansion wave. Meanwhile, the reflected shock wave compresses the oncoming inlet port flow. The inlet port is closed $\left(t_{f}\right)$ as the reflected shock arrives at the inlet $(x=0)$. The expansion wave is generated as the inlet port closes and the outlet port is closed $\left(t_{h}\right)$ a time $t_{V}$ (the reference time) later. Note that this expansion wave effects a nonuniform velocity region at the exhaust port analogous to that in the low pressure exhaust port.

Reverse-flow cycle. In the reverse-flow cycle shown in Fig. 3b, the principle shock first interacts with the undischarged State $D$ fluid which entered through the high pressure port during the last passage charging sequence. Similar to the through-flow above, the principle shock interacts with the contact between State $C$ and $D$, then reflects from the high pressure exhaust port $(x=0)$ and recompresses the State $C$ and State $D$ gases. The inlet port closes when the reflected wave reaches the inlet port where a fan is generated that brings the charging gas and the State D gas to rest at. Note that because the State D gas has already been once around the rotor, it has more entropy than does the new charging gas; therefore, the State D temperature is slightly higher than the charging fluid and State $\mathrm{V}$ is not a uniform state in the reverse-flow cycle. The reference
State $\mathrm{V}$ temperature is actually the mass-averaged temperature of the two streams. The stopping fan also interacts with the contact between the State $C$ and $D$ gases and creates a non-uniform velocity region as the State $C$ fluid is discharged in the exhaust port.

In both high pressure port approaches, shock wave speeds, compression ratios, and entropy production are calculated using the Rankine-Hugoniot relations. The strength of the expansion fan which brings the high pressure inlet port flow to rest in the uniform reference State V sets the static back pressure in the high pressure exhaust port relative to $p_{v}$. This back pressure is that required to insure that the principle shock wave, the reflected shock, and the expansion fan establish the prescribed wave diagrams (Fig. 3) with timing and flow properties that conserve mass and energy. Where necessary, the transmitted and reflected waves of a shock/contact interaction need to be calculated so that velocity and pressure fields are contiguous at contact surfaces. The solution involves inner-loop searches for the principle shock strength and the strength of the shock transmitted at the State $C$ and D interface inside a outer-loop search for the correct stopping fan strength. These searches set the high pressure inlet port total pressure and temperature. The total temperature of the high pressure exhaust port is calculated using a global energy balance (i.e., either Eqn. 2 or Eqn. 4 integrated once around the machine) for the machine. Note that any net work on (or by) the rotor will be made manifest in the energy balance, either through the integral in Eqn. 2 or through specified relative velocity distributions at the port/rotor interfaces. Given the timing, static pressure, total relative total temperature, and mass discharged from the high pressure exhaust port, the remaining properties are obtained.

The high pressure ports are in ways easier to model than the low pressure ports. First, except for the expansion wave which brings the charging flow to rest at the reference State V, all wave timing is set by shock waves which, neglecting gradual opening effects, run at constant speeds in (assumed) uniform regions; further, although the fan strength is initially unknown, the timing of its tail which sets the difference between the high pressure inlet port closing and high pressure exhaust port closing is known; it is unity by definition of the reference state. Second, the high pressure port calculations benefit from earlier low pressure port calculations through the global machine balances; i.e., the mass and energy charged and discharged in the high pressure ports is known a priori. Given the wave timing dictated by the shock speeds, the exact values of the mass-averaged momentum density in the ports is known, facilitating a simple mixing calculation. 


\section{Entropy Production Models}

Entropy production (see Ref. 20 for example treatment) occurs in the wave rotor by shock waves and viscous losses in boundary layers, rotor wakes, separated flows (e.g., in shock/boundary layer interactions), incidence in the inlet ports, mixing in non-uniform outflow port flow fields and at gas/gas interfaces, in vortices generated during passage gradual opening ${ }^{21}$ and closing, and in the interaction of the rotor with the endwalls and with casing (windage). Passage-to-passage leakage and passage-to-casing plenum leakage degrades machine performance by detrimentally redistributing mass and energy in the machine. In practice, leakage is mitigated by controlling rotor/end-wall clearance and by using conventional seals where necessary and is neglected in the in the present work; however, leakage can significantly impact machine performance (e.g., see Ref. 2). Machine performance is further degraded by heat transfer which is also neglected in this work. The entropy produced by the shock compression processes is inherent to the shock relations discussed earlier; however, the entropy produced by shock/boundary layer interaction is neglected in this work. Finally, mixing and redistribution of hot and cold gases caused by multidimensional flow effects (e.g., boundary layers, passage gradual opening and closing dynamics, Rayleigh-Taylor flows, and unbalanced centripetal forces at the gas/gas interfaces ${ }^{21}$ ) adversely impact machine performance but are neglected in this model.

\section{Non-Uniform Mixing Losses}

Diffusion of momentum driven by non-uniform port velocity fields can represent a significant fraction of entropy production within the wave rotor. ${ }^{21}$ This loss mechanism is accounted for in this work by mixing calculations: The mixed-out properties (e.g., total pressure) in outflow ports is obtained by conserving mass, momentum, and energy between the actual nonuniform flow field and an artificial mixed-out, uniform flow field (cf. Ref. 17). In the low pressure exhaust port, for example, the degree of non-uniformity in the discharge velocity (see Eqn. 8) increases with increasing fan strength (or decreasing $\epsilon$ ). The polytropic efficiency of the isentropic expansion and subsequent mixing process is as low as $\eta_{\text {out }}=0.932$ at $\epsilon_{s}=(2 /(\gamma+1))^{2 \Gamma}$, which is the fan pressure ratio at which the discharge is sonic (i.e., $u_{e}=a_{e}$ ), and as high as $\eta_{\text {out }}=1$ in the limit of zero fan strength $(\epsilon=1)$. This efficiency variation influences the optimum fan pressure ratio for a given wave rotor cycle. Other non-uniformities in the exhaust ports arise from boundary layer velocity defects, blade dump area, and passage gradual opening and closing effects. These sources of non-uniformity influence the time-dependent flow leaving the rotor and are discussed below.

In the high pressure exhaust port, the discharge mass and mass-averaged relative total temperature are known from the global mass and energy balances. Having earlier obtained a uniform static pressure and mixed-out momentum density in the exhaust port wave calculations, and assuming that this static pressure is equal to the mixed-out static pressure, the mixed-out properties can be calculated. The effect of mixing entropy and velocity gradients is manifested implicitly in this procedure.

\section{Boundary Layer Loss}

The boundary layer entropy production is estimated at the low pressure exhaust port by estimating the local boundary layer height assuming flat-plate, incompressible, zero pressure gradient flow; the influence of displacement thickness growth on the free stream velocity is neglected for the purpose of this estimate. The spatially-integrated entropy production at the rotor/exhaust port interface is inherent in a mixing calculation at the rotor exit (see Fig. 5) which is based on the time-dependent free stream velocity, a specified (laminar or turbulent) boundary layer velocity profile, and the time-dependent boundary layer height at the rotor exit plane. The flat plate boundary layers on the passage hub, tip, and two blade surfaces are treated. The static pressure and temperature are assumed uniform through the boundary layers so that the local mass, momentum, and energy fluxes can be obtained given that the density and static temperature are also uniform at the rotor/exhaust port interface. A mixing calculation (see Fig. 5) produces the local entropy production given by $\Delta s_{\mu} / R=\ln \left(\left(p_{t, r}\right)_{\infty} /\left(p_{t, r}\right)_{f}\right)$, where $\left(p_{t, r}\right)_{\infty}$ is the local free-stream total pressure and $\left(p_{t, r}\right)_{f}$ is the instantaneous mixed-out total pressure. The boundary layer entropy production, $\Delta s_{b l} / R$, identified in Eqn. 17, is the mass-average of the local entropy production, $\Delta s / R$, over the entire discharge process $\left(0 \leq t \leq t_{b}\right)$ in the ${ }^{\mu}$ low pressure exhaust port. The expansion ${ }^{b}$ fan entropy production, $\Delta s_{f} / R$, identified in Eqn. 7, is the mass-average of the same local entropy production, $\Delta s_{\mu} / R$, but now only during the portion of the discharge to the uniform velocity region $(0 \leq t \leq t)$ of the low pressure exhaust port. The viscous losses internal to the rotor reduce the free stream velocity (through the influence of $\Delta s_{f} / R$ in Eqn. 7) and increase the discharge static temperature for a given fixed fan pressure ratio. 
Boundary layer entropy production during the low pressure inlet port charging process and the charging and exhausting processes in the high pressure ports is estimated using the mass-averaged boundary layer entropy production in the low pressure exhaust port $\left(\Delta s_{b l} / R\right)$ and the scaling (here for laminar flow)

$$
S_{\mu} / R \equiv \iint_{t}\left(\gamma \Phi_{\mu} / a^{2}\right) d V d t-\left(\rho M^{3}\left(x / L_{T}\right)\right)^{\frac{1}{2}}
$$

where $S_{\mu} / R$ is normalized entropy production, $\Phi_{\mu}\left(\sim \mu(\partial u / \partial y)^{2}\right)$ is the local viscous dissipation, $M$ is the local free-stream axial Mach number, and $\left(x / L_{T}\right)$ is the fraction of the passage through which the local fluid particle has traveled since coming on-board or last at rest. The position and time-averaged density, Mach number, and average length traveled by a fluid package is crudely estimated in each port. The relative total pressure of inlet ports are then increased by

$$
\left(p_{t, r}\right)_{\text {new }}=\left(p_{t, r}\right)_{\text {old }} e^{\left(\Delta s_{b l} / R\right)_{t}}
$$

where $\left(\Delta s_{b l} / R\right)_{l}$ is the mass-averaged boundary layer entropy production of the $l^{\text {th }}$ port, implying that more pressure is required to overcome the loss; the pressure in the high pressure exhaust port is similarly reduced.

\section{Blade Blockage}

The finite blade thicknesses are typically 7 to $15 \%$ of the passage width and provide blockage that results in total pressure loss and influences port mass flow rates by reducing rotor flow area. The total pressure loss for flow entering the rotor is low for the axial Mach numbers $(\leq 0.3)$ typical of wave rotors and is neglected in this work. In the outflow ports, a quasi-static mixing calculation for the model problem shown in Fig. 5b provides an estimate of entropy production due to sudden area increase. This calculation combines with the viscous calculation above to simulate losses due to blade wakes. The base pressure shown in Fig. $5 \mathrm{~b}$ is calculated using

$$
p_{b}=p_{f}-c_{b} \frac{1}{2} \rho u_{f}^{2}
$$

where $p_{\mathrm{f}}$ and $u_{\mathrm{f}}$ are the static pressure and axial velocity at the rotor exit, $p_{b}$ is the base pressure, and $c_{b}$ is a constant (0.15 in this work [cf. Ref. 22]).

\section{Passage Gradual Opening and Closing}

The wave rotor is inherently a partial admission device. The rotor passages gradually, rather than instantaneously, open to and close off from the relatively steady port flows.

Inlet Ports. While a passage is partially open to an inlet port, significant entropy is produced as flow separates off the stator end-wall as shown in Fig. 6a. During the gradual opening, the passage is partially exposed to the port flow and partially exposed to the end-wall where the static (base) pressure (see Eqn. 24) is dependent on the port flow conditions. A simple mixing calculation provides an estimate of entropy production during the passage opening or closing by neglecting the effect of gas dynamic waves during this time. (These include expansion waves that propagate into the inflow port and reduce the total pressure of the incoming fluid, compression waves that move into the passage during the passage gradual opening, and shocks emitted into the inlet port during passage gradual closing. ${ }^{14}$ ) Further, although total pressure of the fluid entering partially opened passages is nominally lower than that in the port free-stream due to boundary layer growth on the port walls, the flow is assumed to enter the rotor with the mean port flow properties. The total entropy produced during the passage opening process is obtained by integrating in time the entropy produced in quasi-static, constant-area mixing of the port flow and base pressure fluxes of the partially opened passage (see Fig 6a). Dividing the integrated entropy production by the mass of the gas entering the passage during the gradual opening $\left(\boldsymbol{m}_{\tau}\right)$ provides the mass-averaged specific entropy production $\left(\Delta s_{\tau} / R\right)$ of the gas entering during the gradual opening. A corrected inflow port total pressure is then obtained from

$$
\left(p_{t, r}\right)_{\text {new }}=\left(p_{t, r}\right)_{\text {old }} e^{\left(m_{\tau} / m_{\text {in }}\right) \Delta s_{\tau} / R}
$$

where the "new" inlet port total pressure is higher than the "old" pressure calculated earlier and $m_{\text {in }}$ here represents the mass entering the wave rotor passage as it traverses the port. Note that because the flow entering the passage is assumed uniform, and because the base pressure is based on the port flow only, the entropy produced during passage opening and closing are the same so that typically $\Delta s / R$ is simply doubled to account for both opening and closing in a given port.

Outlet Ports. Figure $6 \mathrm{~b}$ shows a model for the effect of gradual opening in an outflow port. Entropy is produced in a mixing calculation for the mixed-out properties at the passage exhaust, where again, the 
reflection of the incoming waves has been neglected. Although little entropy is produced during the partial exhaust process, the gradual opening effects non-uniform mass, momentum, and energy distributions and thus increases the entropy produced in the global mixing in the outlet port (discussed above). Further, the passage gradual opening and closing reduces the discharged mass (when compared to that from an instantaneously opened passage) for a given fan pressure ratio and port timing; this reduces machine performance at a fixed $\epsilon$. The reduction in discharged mass might be recovered by increasing the fan pressure ratio (reducing $\epsilon$ ); however, in doing so, typically viscous losses are increased, so that, a new optimum $\epsilon$ may be realized, but original (zero opening time) performance is not recovered.

\section{Incidence Loss}

It is assumed that the wave rotor duct angles are designed so that at mid-span the flow enters the passages with zero incidence. The through-flow and tangential components of velocity are assumed radially uniform so that away from mid-span incidence is nonzero, leading to an entrance loss of relative total pressure. The inlet port average axial velocity component, $u$, and local speed of sound are obtained from the 1-D gas dynamic calculations described earlier. The radially uniform tangential velocity component is set by $u_{\theta}=\Omega \bar{R}+u \tan \beta$, where $\Omega$ is the constant rotor angular speed, $\beta$ is the blade angle, and $\bar{R}$ is the radius at mid-span. The kinetic energy invested in the tangential velocity decrement $\mid \Omega R-\Omega r) \mid$ is assumed lost (cf. Ref. 23) through viscous dissipation so that the relative total pressure available to work on the fluid, $\left(p_{t, r}\right)_{2}$, is less than the local port total pressure, $\left(p_{t, r}\right)_{1}$. The net total pressure loss due to incidence is obtained by calculating a mass-averaged pressure ratio using the hub-to-tip distribution of local pressure ratio $\left(p_{t, r}\right)_{2} /\left(p_{t, r}\right)_{1}$. Given the inlet port conditions, a new total pressure is calculated using the mass-averaged pressure ratio, reflecting that higher total pressure is required to drive the flow due to the incidence loss.

\section{Application to a Three-Port Wave Rotor}

A three-port divider cycle divides a medium total pressure $\left(p_{t, \text { in }}\right)$ inlet stream into two streams, one of higher total pressure $\left(p_{t, h i}\right)$ and one of lower total pressure $\left(p_{t, l o}\right)$. As shown in Fig. $2 \mathrm{~b}$, the medium and high pressure ports use the same wave diagram as the through-flow high pressure ports (Fig. 3a); however, in the three-port, the mass discharged from the high pressure exhaust port is equal to a fraction $\beta \equiv m_{h i} / \boldsymbol{m}_{i}$ of the medium pressure inlet flow and may include part or all of State $Q$ fluid and part or none of the high pressure inlet flow. The remaining mass $(1-\boldsymbol{\beta}) m_{\text {in }}$ is that discharged from the low pressure port. Figure 7 shows a plot of the pressure ratios $p_{t, h i} / p_{t, \text { in }}$ and $p_{t, l o} / p_{t, i n}$ as a function of the mass flow fraction, $\beta$, for the Power Jets (R\&D), Ltd. wave rotor. ${ }^{1}$ Figure 7 compares the predictions of the current model with experimental curves for the conditions shown: $6000 \mathrm{rpm}$, $T_{t, \text { in }}=554 \mathrm{R}(308 \mathrm{~K}), p_{t, l o} \simeq 1 \mathrm{~atm}(0.101 \mathrm{MPa})$. Note that each point along the curves of the present study represents an on-design wave rotor-i.e., one redesigned for that operating point. The experimental curves are data from a single machine, running at constant rotor speed, with fixed port timing. Further, the Power Jets rotor had axial ducts introducing no preswirl; non-negligible work is likely done by the rotor and this might in-part explain the difference in the qualitative behavior at low pressure ratios. Figure 7 is intended only to illustrate that the qualitative trend of the model predictions and the loss levels are similar. Indeed, it would be expected that the results of the present work would everywhere over-predict the actual machine performance, suggesting that in this case the predicted entropy production levels (e.g., boundary layer loss) are too high. Although beyond the scope of the present work, this suggests using empirical constants to "tune" the entropy production models using experimental data or results from calibrated codes (e.g., that of Ref. 13).

\section{Wave Rotor Design Application}

The computational efficiency and accuracy of the described wave rotor model makes it amenable to engine system design-point studies. Consider an example small turboshaft engine with $2390 \mathrm{R}$ turbine inlet temperature and $5.0 \mathrm{lb}_{\mathrm{m}} / \mathrm{s}$ compressor discharge air at $7.77 \mathrm{~atm}$ and $1080 \mathrm{R}$ (cf. Ref. 12). Given this information, it is the task of the designer to provide an optimum straightbladed wave rotor design to top this engine. "Optimum" design in this context means one in which the wave rotor low pressure inlet mass flow rate is $5.0 \mathrm{lb}_{\mathrm{m}} / \mathrm{s}$, the pressure ratio $\left(\left(p_{t, r}\right)_{\text {out }} /\left(p_{t, r}\right)_{\text {in }}\right)$ in the low pressure ports is maximized, and the interface between the inflow gas (cold air) and the undischarged hot (burned) air moves at least half way $\left(x / L_{\tau}\right)$ through the wave rotor. Maximizing the (zero-net shaft power) wave rotor pressure ratio maximizes the benefit of topping in terms of engine net shaft power per mass flow rate and specific fuel consumption. The third requirement addresses rotor cooling requirement for the reverse-flow 
type four-port ${ }^{12}$ and means that the mass discharge fraction $\left(m_{\text {out }} / m_{v}\right)$ should be $\geq 0.5$.

Taussig has previously provided a wave rotor design process and identified non-dimensional design parameters. ${ }^{6}$ More recently, Wilson and Paxson used similar analysis to obtain rotor designs that optimize absolute frame pressure ratio. ${ }^{24}$ Rotor design is accomplished in the present work by optimizing the rotor performance (or pressure ratio)-under the restrictions mentioned above-by varying the fan pressure ratio, the rotor length, the passage aspect (length-to-tip width) ratio, and the hub-to-tip ratio. Before focusing attention on the point design for the example engine, however, it is insightful to consider first the relative impact of loss mechanisms using values for these non-dimensional parameters typical of optimized machines. The impact of coolant bleed fraction is also assessed.

\section{Incremental Impact of Loss Mechanisms}

Figure 8 compares predicted absolute total pressure ratio versus mass discharge fraction. Each point, on each curve, corresponds to an on-design wave rotor operating at a fixed fan pressure ratio or mass discharge fraction. The fan pressure ratio $(\epsilon)$ is indicated by " $x$ " and is varied parametrically in the following sequence (starting at the right end of the curves): $0.3,0.35,0.40$, $0.45,0.5,0.6$. For example, the optimum pressure ratio of Curve $A$ occurs very near $\epsilon=0.35$. Curve $A$ is performance for wave rotors with 0.25 rotor tip Mach numbers and no gradual opening, boundary layer, blade blockage, or incidence losses. Curve B shows the corresponding relative total pressure ratio (see Fig. 4 and also comments in earlier wave rotor optimization study in Ref. 24). The discrepancy between the two curves increases with increasing rotor Mach number. The optimum $\epsilon$ in terms of pressure ratio for both Curves A and $B$ is near 0.35 where the pressure ratio of Curve $A$ is 1.366 at a mass discharge fraction of 0.708 . Curve $C$ shows performance for the same rotor, now with nondimensional passage gradual opening time specified as 0.4 . The passage gradual opening significantly reduces the mass discharge fraction and shifts the optimum pressure ratio to an $\epsilon$ near 0.4. Curve $D$ shows the effect of blade surface boundary layer entropy production. Here the opening time is zero and an example passage aspect ratio of 16:1 (rotor length-towidth at rotor tip) is used. The impact on pressure ratio is similar to the example opening time loss; however, the mass discharge fraction is not reduced as severely. Note that with the hub-to-tip ratio still set at unity, the influence of the hub and tip wall boundary layers is not manifested in Curve D. Curve $\mathrm{E}$ combines the opening time and viscous losses; again, the pressure ratio and mass fraction are reduced and the optimum $\epsilon$ now moves to 0.42 . Curve $\mathrm{F}$ adds the effect of $8 \%$ blade blockage-the machine pressure ratio and mass discharge fraction are again both reduced, and the optimum $\epsilon$ moves to near 0.45 . Finally, Curve $G$ shows that incidence loss and boundary layer loss on the hub and tip shroud-included by setting an example hub-totip ratio of $2 / 3$-further reduce the pressure ratio and mass discharge fraction (to $\propto 0.5$ ) and move the optimum $\epsilon$ to 0.45 . Noting that the mass discharge fraction at $\epsilon$ of 0.45 on Curve $G$ just meets the 0.5 design requirement, a margin is introduced (and a slight performance penalty is incurred) by selecting $\epsilon$ of 0.4 as a suggested design value for these loss levels. The impact of extracting coolant bleed flow from the wave rotor (e.g., as required for turbine cooling in some gas turbine engine application $\mathrm{s}^{12}$ ) is indicated parametrically in Fig. 8 for $\epsilon=0.4$ and Curve $G$ conditions.

By comparing the pressure gain (i.e., 0.24 for a pressure ratio of 1.24) on Curves $A$ and $G$, at fan pressure ratio of 0.4 , losses are seen to reduce pressure gain by $30 \%$. The $30 \%$ is caused by the following estimated linear incremental losses: gradual opening $28 \%$; boundary layer $57 \%$; blade blockage $8.1 \%$; incidence $4.5 \%$. Further, the mass discharge fraction is reduced by $22 \%$ from 0.676 to 0.528 as losses are accounted for. Finally, considering the parametric variation in coolant bleed fraction clearly shows that a heavy performance penalty is paid: Each $5 \%$ cooling increment reduces pressure gain by $13 \%$.

\section{Point Design}

In order to carry out the wave rotor design at the 5.0 $1 b_{m} /$ s engine mass flow rate, the fan pressure ratio is first fixed at 0.4 based on the analysis above. The point design is carried out for a machine with two cycles per rotor and an example coolant bleed fraction of $6.9 \%$. (In a more detailed analysis, the selection of the number of cycles per rotor might well be influenced by duct weight, cooling, and aerodynamic issues that will impact a figure-of-merit for the overall engine system.) The rotor length and hub-to-tip ratio are varied parametrically. For each rotor length and hub-to-tip ratio combination, the optimum rotor passage aspect (length-to-tip width) ratio is determined by searching from some lower value (usually 10 ) incrementally upward. The pressure ratio increases monotonically with passage aspect ratio until a maximum is reached. At each aspect ratio, an inner iteration determines the one rotor Mach number that satisfies the $5.0 \mathrm{lb}_{\mathrm{m}} / \mathrm{s}$ specified inlet mass flow rate requirement. Figures 9 and 10 present the results of this parametric analysis. Figure 9 compares the pressure ratio versus rotor length for wave rotors of various hub-to-tip ratios. Each point, on each 
Table 2. Wave rotor design for $5.0 \mathrm{lb} / \mathrm{m}$ turboshaft engine topping cycle with $2390 \mathrm{R}$ turbine inlet temperature, $1080 \mathrm{R}$ and $7.77 \mathrm{~atm}$ compressor discharge, and $6.9 \%$ bleed fraction.

\begin{tabular}{||c|c||c|c||}
\hline Parameter & Value & Parameter & Value \\
\hline \hline Absolute Total Temperature Ratio & 2.212 & Reference Time $\left(t_{v}, \mathrm{~ms}\right)$ & 0.234 \\
\hline Absolute Total Pressure Ratio & 1.204 & Non-Dimensional Opening Time & 0.409 \\
\hline Fan Pressure Ratio & 0.4 & Non-Dimensional Cycle Time & 0.247 \\
\hline Ratio of Specific Heats & 1.315 & Total Rotor Passages & 44 \\
\hline Cycles per Rotor & 2 & Rotor Tip Radius (inches) & 3.35 \\
\hline Rotor Length & 7.0 & Passage Width at Tip (inches) & 0.443 \\
\hline Hub-to-Tip Ratio & 0.667 & Rotor Passage Height (inches) & 1.12 \\
\hline Passage Aspect Ratio & 15.8 & RPM & 13,167 \\
\hline Rotor Tip Mach Number* & 0.247 & Rotor Tip Speed (ft/s) & 385 \\
\hline Blade Thickness / Passage Tip at Width & 0.08 & Rotor Equivalent Tip Speed (ft/s) & 267 \\
\hline
\end{tabular}

*Based on compressor discharge total speed of sound.

curve, corresponds to an on-design $5.0 \mathrm{lb}_{\mathrm{rn}} / \mathrm{s}$ wave rotor point design. Figure 9 shows that an optimum hub-totip ratio exists somewhere between the 0.6 hub-to-tip ratio and 0.9 where performance is clearly lower than at the 0.667 or 0.8 hub-to-tip ratios. It is noted that performance is slightly higher at the optimum of 9 or 10 inch rotor length on 0.8 hub-to-tip ratio as compared to the optimum at 8 or 9 inches on the 0.667 curve; however, considering that rotor tip radius grows nearly quadradically with increasing hub-to-tip ratio and that the optimum rotor length is also seen to grow with hubto-tip ratio, the 0.667 rotor curve is selected in order to minimize rotor size and weight. Further, although the optimum pressure ratio on the 0.667 curve occurs near rotor length of 9 inches, nearly the same performance is realized at 7 inches; again, for weight considerations then, the 7 inch length is selected for the design point. In Fig. 10 the rotor length is fixed at 7 inches and the hub-to-tip ratio is varied to narrow in on the optimum. Remarkably, the optimum occurs at $2 / 3$. Table 2 provides the point design for the $5.0 \mathrm{lb}_{\mathrm{m}} / \mathrm{s}$ wave rotor with an example coolant bleed fraction of $6.9 \%$. The wave rotor pressure ratio is 1.204 at a mass discharge fraction of 0.528 .

\section{Summary}

A wave rotor model based on macroscopic mass and energy balances, one-dimensional gas dynamic wave processes, and entropy production models is described. Comparisons with 1-D CFD calculations show that the model accurately predicts the wave rotor pressure ratio for the "ideal" case that accounts only for entropy production in shock waves and in mixing non-uniform exhaust port flows. Simple loss models that account for entropy production in boundary layers and in separating flows caused by passage gradual opening and closing, blade blockage, and incidence were described. The relative impact of these loss mechanisms was estimated. Comparison of model predictions with three-port divider cycle experimental data indicated that entropy production was slightly over-predicted by the loss models; though beyond the scope of the present study, this suggested tuning the loss models using empirical factors. The modeling approach presented in this work readily accommodates improvements to the entropy production models. Future loss modeling should address leakage and heat transfer.

The wave rotor model requires minimal computational investment, making it well suited for parametric studies. An example wave rotor point design illustrated the applicability of the model to wave rotor design and 
optimization. The described wave rotor model has been integrated into a system code which estimates the benefit of wave rotor topping in turboshaft engines. For example, the system code shows that wave rotor topping increases the shaft horsepower of the engine considered in the example design application by $19 \%$ with a concurrent $17 \%$ reduction in specific fuel consumption. Future work will likely extend the engine system code to include wave rotor weight estimates with an aim toward optimizing wave rotor geometry on a power per engine weight basis.

Future effort should also extend model capability to off-design performance predictions. Indeed, by fixing the wave rotor geometry (e.g., rotor length and tip radius, passage aspect ratio, and hub-to-tip ratio) at the optimized design-point geometry, the current model might well provide a good first approximation to offdesign performance, even though the port timing is readjusted at each off-design condition. A next step would involve fixing both rotor geometry and port timing in order to include the performance impact of mis-timed waves.

Finally, the model presented in this work is applicable to wave engines with aerodynamic blading that produce net shaft power rather than pressure gain. Near term future work should seek to characterize the wave engine, in terms of design and expected performance levels, using the macroscopic balance modeling approach presented here.

\section{Acknowledgements}

The author is grateful for the valuable suggestions and generous time commitment offered by Dr. Louis $M$. Larosiliere (U.S. Army Research Laboratory) with regards to this paper. The author thanks Dr. Jack Wilson (NYMA, Inc.) and Dr. Daniel E. Paxson (NASA Lewis Research Center) for interesting discussions on wave rotor and for assistance with model validation.

\section{References}

${ }^{1}$ Kentfield, J. A. C., "The Performance of PressureExchanger Dividers and Equalizers," J. Basic Eng., Sept. 1969, pp. 361-370.

${ }^{2}$ Wilson, J. and Fronek, D., "Initial Results from the NASA Lewis Wave Rotor Experiment," AIAA-93-2521, June, 1993; also NASA TM-106148.

${ }^{3}$ Goldstein, A. W., Klapproth, J. F., and Hartmann, M. J., "Ideal Performance of Valved-Combustors and Applicability to Several Engine Types," ASME-57-A102, 1957.

${ }^{4}$ Meyer, A. "Recent Developments in Gas Turbines," Mech. Engineering, 69, 1947, pp. 273-277.

${ }^{5}$ Zauner, E., Chyou, Y.-P., Walraven, F., and Althaus, R., "Gas Turbine Topping Stage Based on Energy Exchangers: Process and Performance," ASME-93-GT58, May, 1993.

${ }^{6}$ Taussig, R. T., "Wave Rotor Turbofan Engines for Aircraft," ed. Sladky, J. F., Jr., Machinery for Direct Fluid-Fluid Energy Exchange, AD-07, The American Society of Mechanical Engineers, New York, USA, Dec., 1984, pp. 9-45.

${ }^{7}$ Pearson, R. D., "A Gas Wave-Turbine Engine Which Developed 35 HP and Performed over a 6:1 Speed Range," eds. Shreeve, R. P. and Mathur, A., Proc. 1985 ONRANAVAIR Wave Rotor Research and Technology Workshop, Report NPS-67-85-008, Naval Postgraduate School, Monterey, CA, pp. 125-170.

${ }^{8}$ Azoury, P. H., "An Introduction to the Dynamic Pressure Exchanger," Proc. Inst. Mech. Eng., 180, Part 1, 1965-1966, pp. 451-480.

${ }^{9}$ Ed. Sladky, J. F., Jr., Machinery for Direct FluidFluid Energy Exchange, AD-07, The American Society of Mechanical Engineers, New York, USA, Dec., 1984.

${ }^{10}$ Rose, P. H., "Potential Applications of Wave Machinery to Energy and Chemical Processes," eds., Lifshitz, A. and Rom, J., Shock Tubes and Wave, Proc. 12th Int. Symposium on Shock Tubes and Waves, The Magnes Press, Jerusalem, Israel, July, 1979, pp. 3-30.

${ }^{11}$ Eds. Shreeve, R. P., and Mathur, A., Proc. 1985 ONRANAVAIR Wave Rotor Research and Technology Workshop, Report NPS-67-85-008, Naval Postgraduate School, Monterey, CA, May, 1985.

${ }^{12}$ Welch, G. E., Jones, S. M., and Paxson, D. E., "Wave Rotor-Enhanced Gas Turbine Engines," AIAA 95-2799, July, 1995; also NASA TM-106998 and ARLTR-806.

${ }^{13}$ Paxson, D. E., "Comparison Between Numerically Modeled and Experimentally Measured Wave-Rotor Loss Mechanisms," J. Propulsion and Power, 11, No. 5, Sept.-Oct., pp.908-914; also NASA-TM-106279. 
${ }^{14}$ Welch, G. E. and Chima, R. V., "Two-Dimensional CFD Modeling of Wave Rotor Flow Dynamics," Proc. $I^{\text {th }}$ Computational Fluid Dynamics Conference, Part 1, AIAA-93-3318-CP, Orlando, FL, July 6-9, 1993, pp. 234-247; also NASA TM-106261.

${ }^{15}$ Larosiliere, L. M., "Wave Rotor Charging Process: Effects of Gradual Opening and Rotation," J. Propulsion and Power, Technical Note, 11, No. 1., Jan.-Feb., pp. 178-184.

${ }^{16}$ Rudinger, G., Wave Diagrams for Nonsteady Flow in Ducts, D. Van Nostrand Company, Inc., New York, USA, 1955, pp. 186-193.

${ }^{17}$ Foa, J. V., Elements of Flight Propulsion, Wiley, New York, 1960, pp. 161-166.

${ }^{18}$ Mathur, A., "A Brief Review of the G. E. Wave Engine Program (1958-1963)," eds. Shreeve, R. P., and Mathur, A., Proc. 1985 ONRNAVAIR Wave Rotor Research and Technology Workshop, Report NPS-67-85008, Naval Postgraduate School, Monterey, CA, May, 1985, pp. 171-193.

${ }^{19}$ Berchtold, M. "The Comprex as a topping spool in a gas turbine engine for cruise missile propulsion," ibid., pp. 284-290.
${ }^{20}$ Kirkwood, J. G. and Crawford, B., Jr., "The Macroscopic Equations of Transport," J. Phys. Chem., 56, Dec., 1952, pp. 1048-1051.

${ }^{21}$ Keller, J. J., "Some Fundamentals of the Supercharger Comprex ${ }^{\mathbb{Q}}$," ed. Sladky, J. F., Jr., Machinery for Direct Fluid-Fluid Energy Exchange, AD-07, The American Society of Mechanical Engineers, New York, USA, Dec., 1984, pp. 47-54.

${ }^{22}$ Denton, J. D., "Loss Mechanisms in Turbomachines," J. Turbomachinery, 115, No. 4, Oct. 1993, p. 627.

${ }^{23}$ Roelke, R. J., "Miscellaneous Losses," ed. Glassman, A., Turbine Design and Application, NASA SP-290, NASA Center for Aerospace Information, Maryland, USA, p. 245.

${ }^{24}$ Wilson, J. and Paxson, D. E., "Optimization of Wave Rotor for Use as Gas Turbine Engine Topping Cycles," SAE-951411, May, 1995; also NASA TM106951.

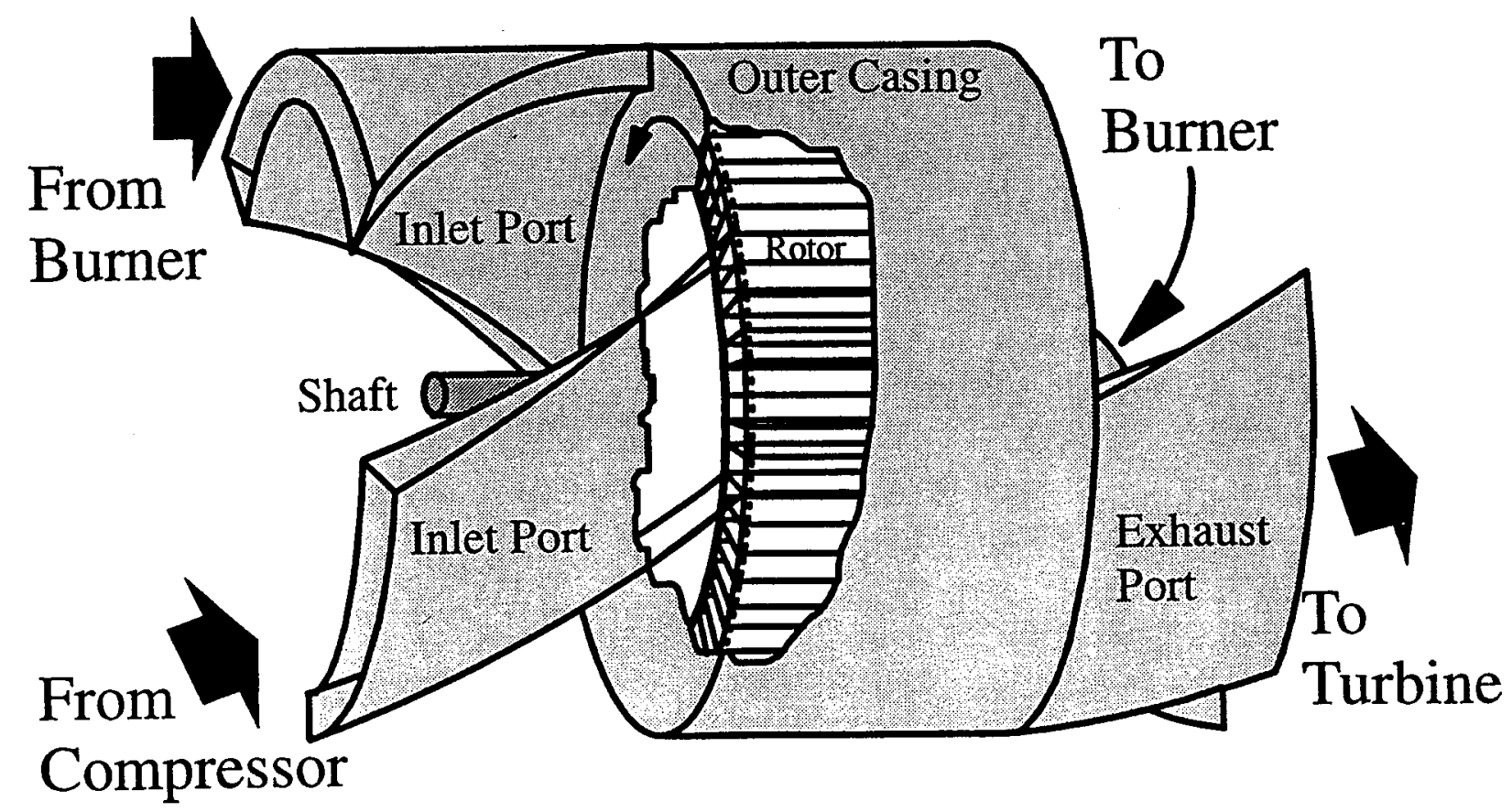

Figure 1. Four-port wave rotor schematic diagram. 


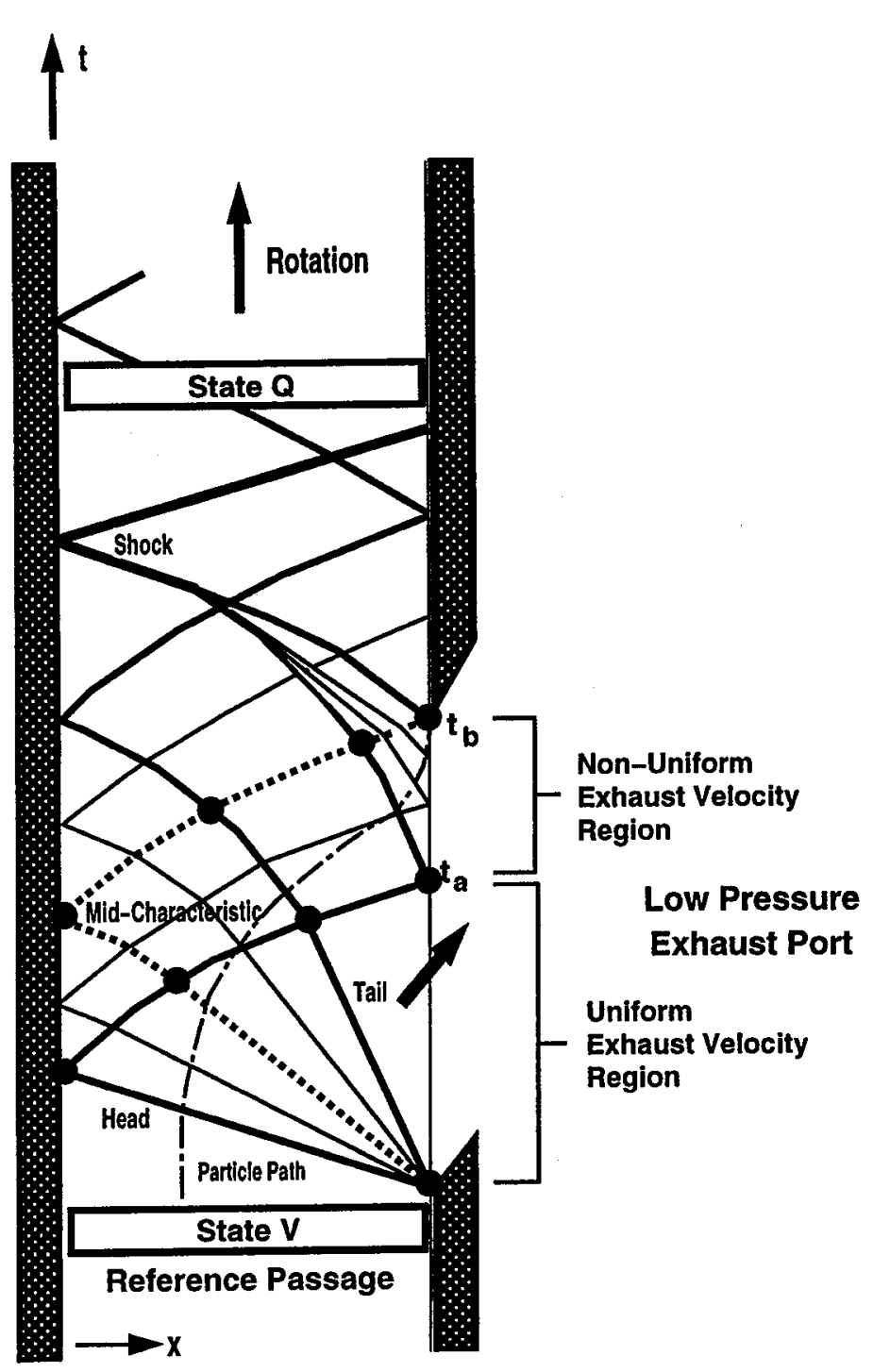

a.) Wave rotor passage exhaust process.

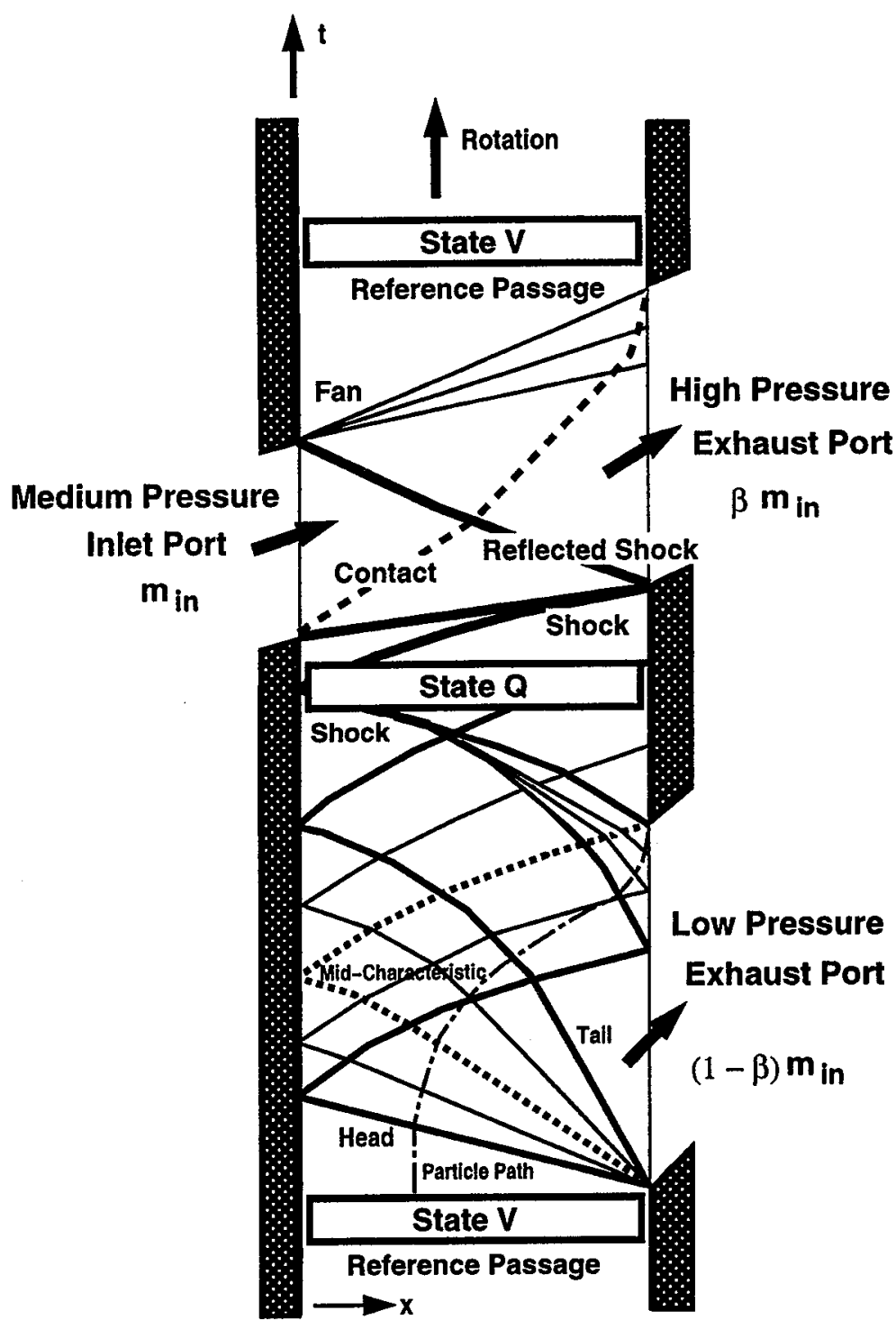

b.) Three-port divider cycle. ${ }^{2}$

Figure 2. Position-time diagrams of a.) wave rotor passage exhaust process and $b$.) three-port divider cycle. 


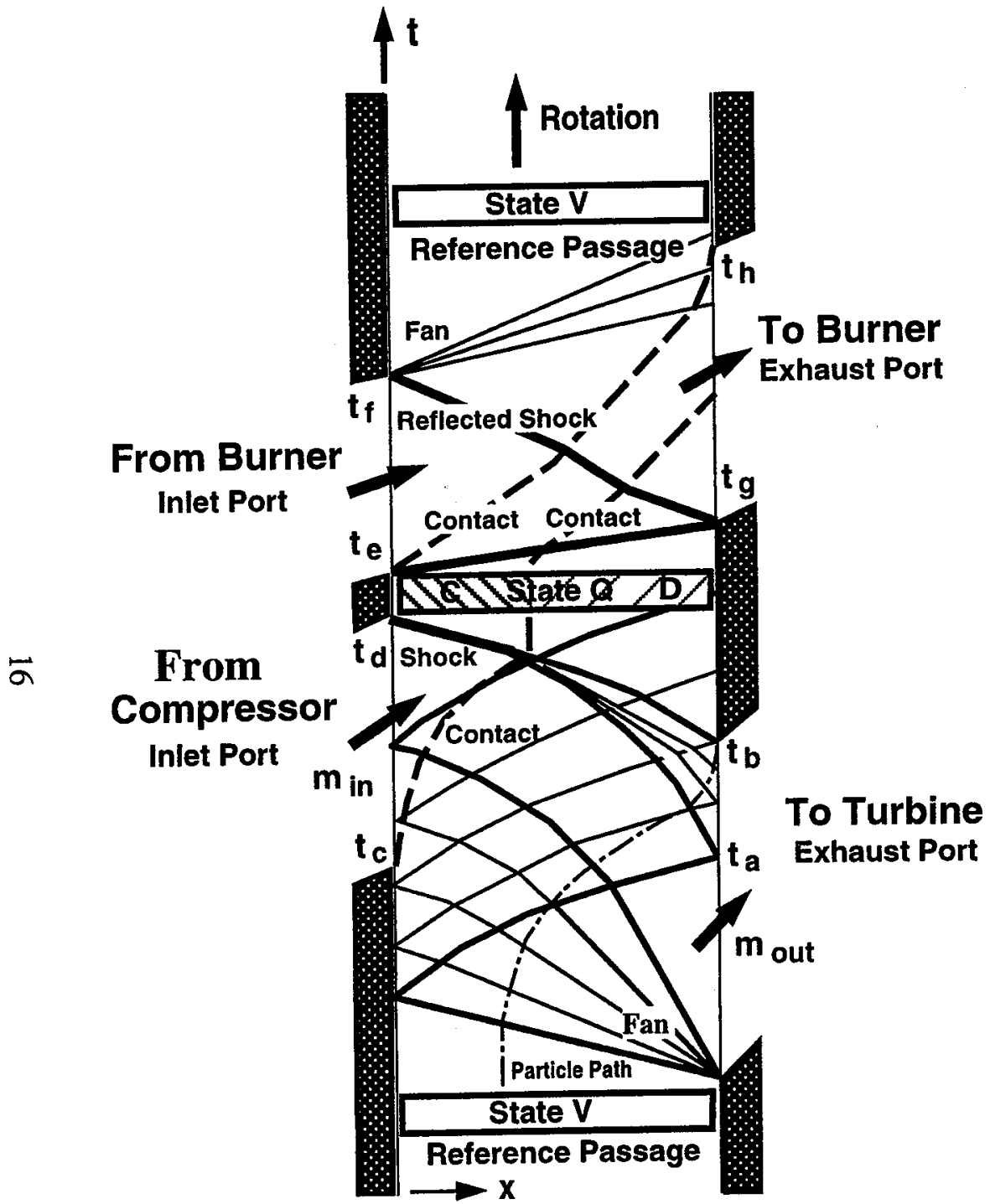

a.) Through-Flow Cycle

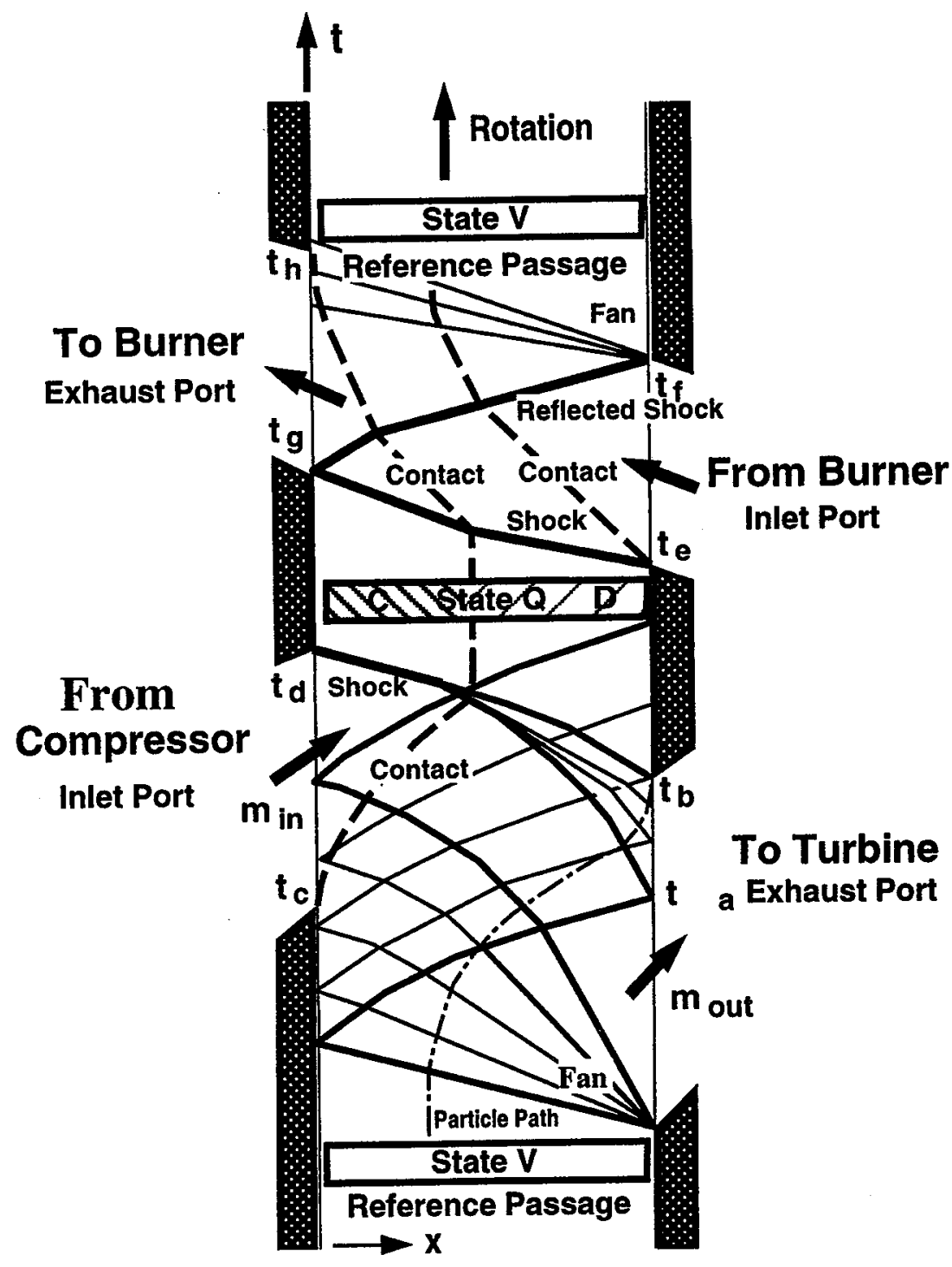

b.) Reverse-Flow Cycle

Figure 3. Position-time diagrams for a.) through-flow four-port cycle and b.) reverse-flow four-port cycle. 


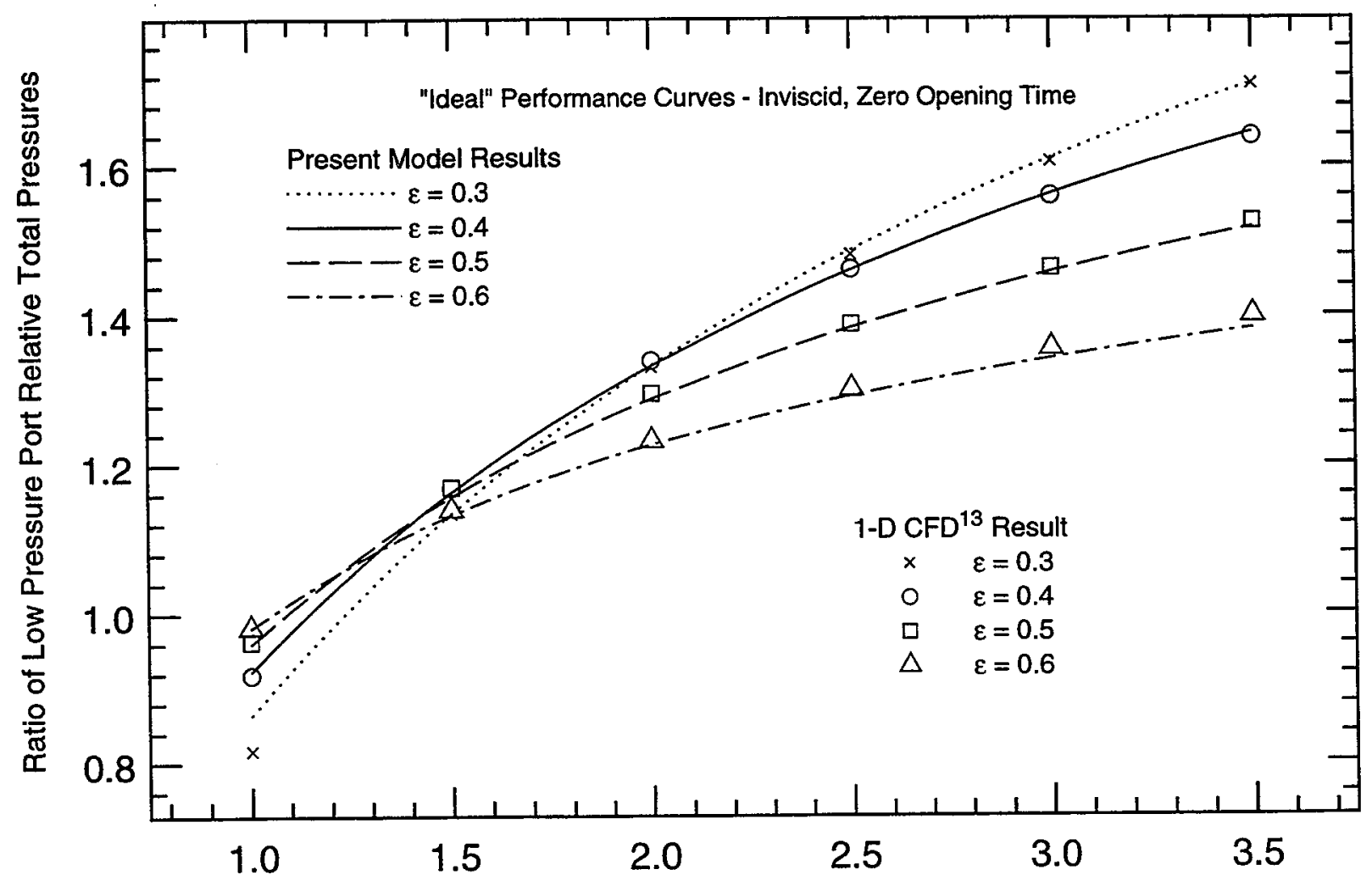

Ratio of Low Pressure Port Relative Total Temperatures

Figure 4. Comparison of computed ratio of low pressure port relative total pressures as a function of relative total temperature and fan pressure ratio from present model and 1-D CFD code. ${ }^{13}$

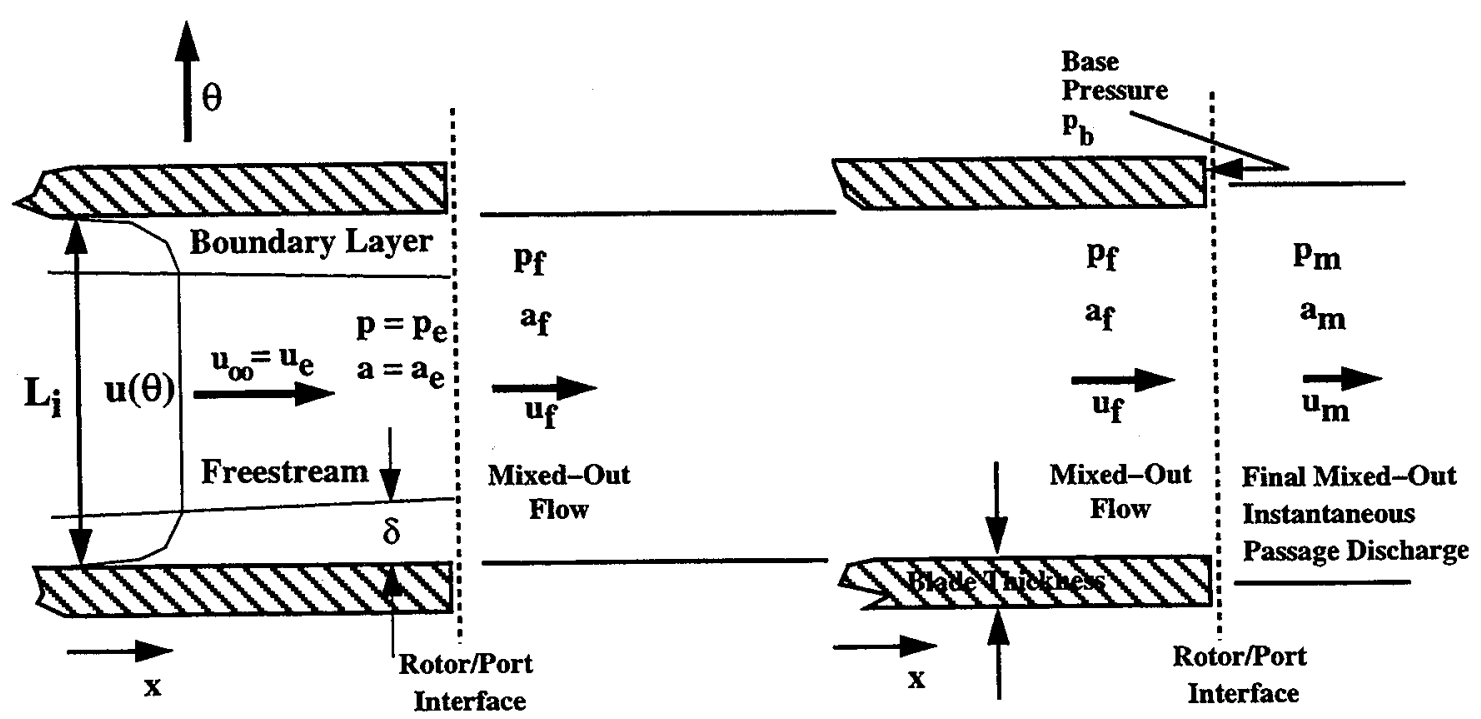

a.) Mixing-calculation for boundary layer.

b.) Mixing-calculation for blade dump area.

Figure 5. Schematic diagrams of mixing calculations for estimating boundary layer and blade dump losses. 


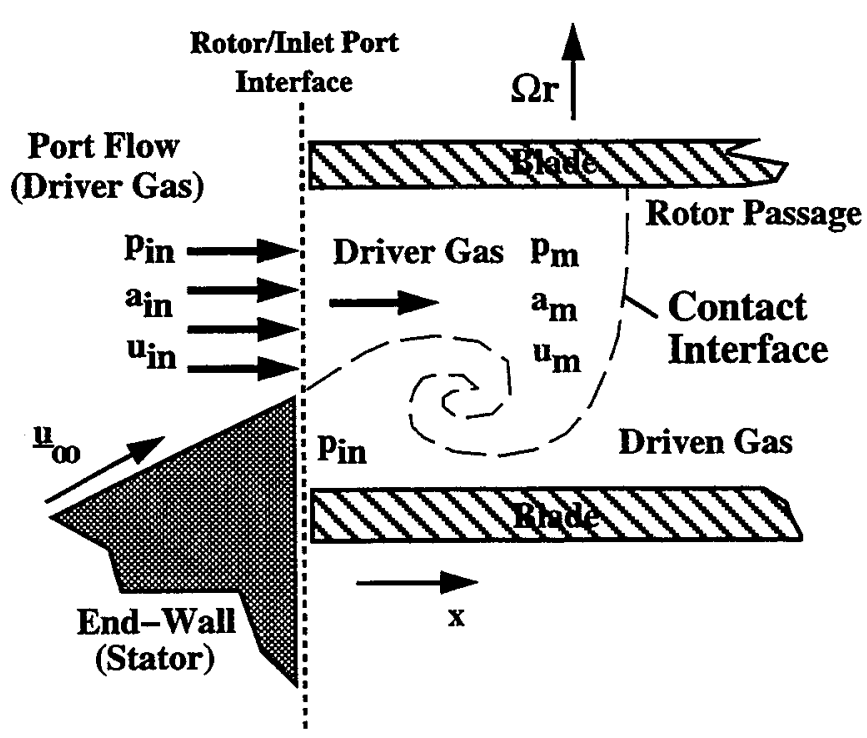

a.) Mixing-calculation for passage gradual opening at inlet port.

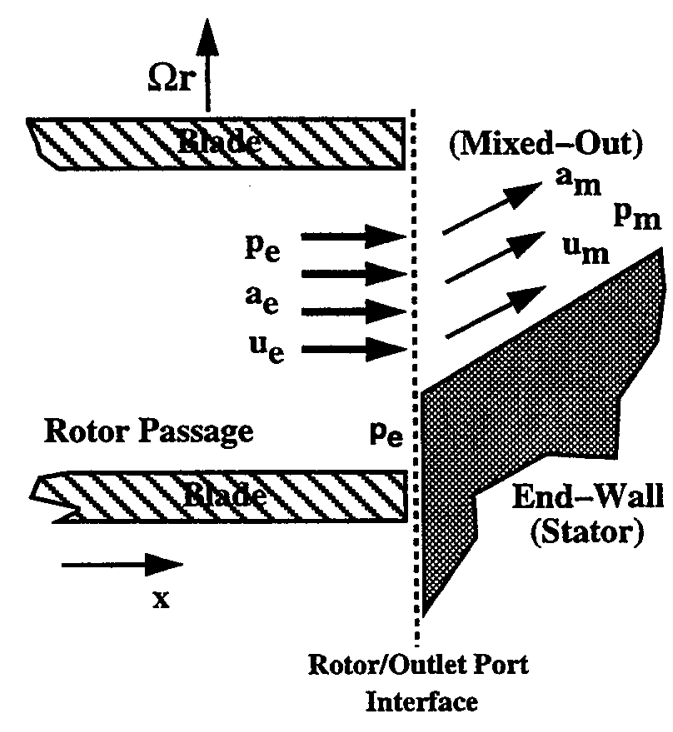

b.) Mixing-calculation for passage gradual opening at outlet port.

Figure 6. Schematic diagrams of mixing calculations for passage gradual opening and closing losses.

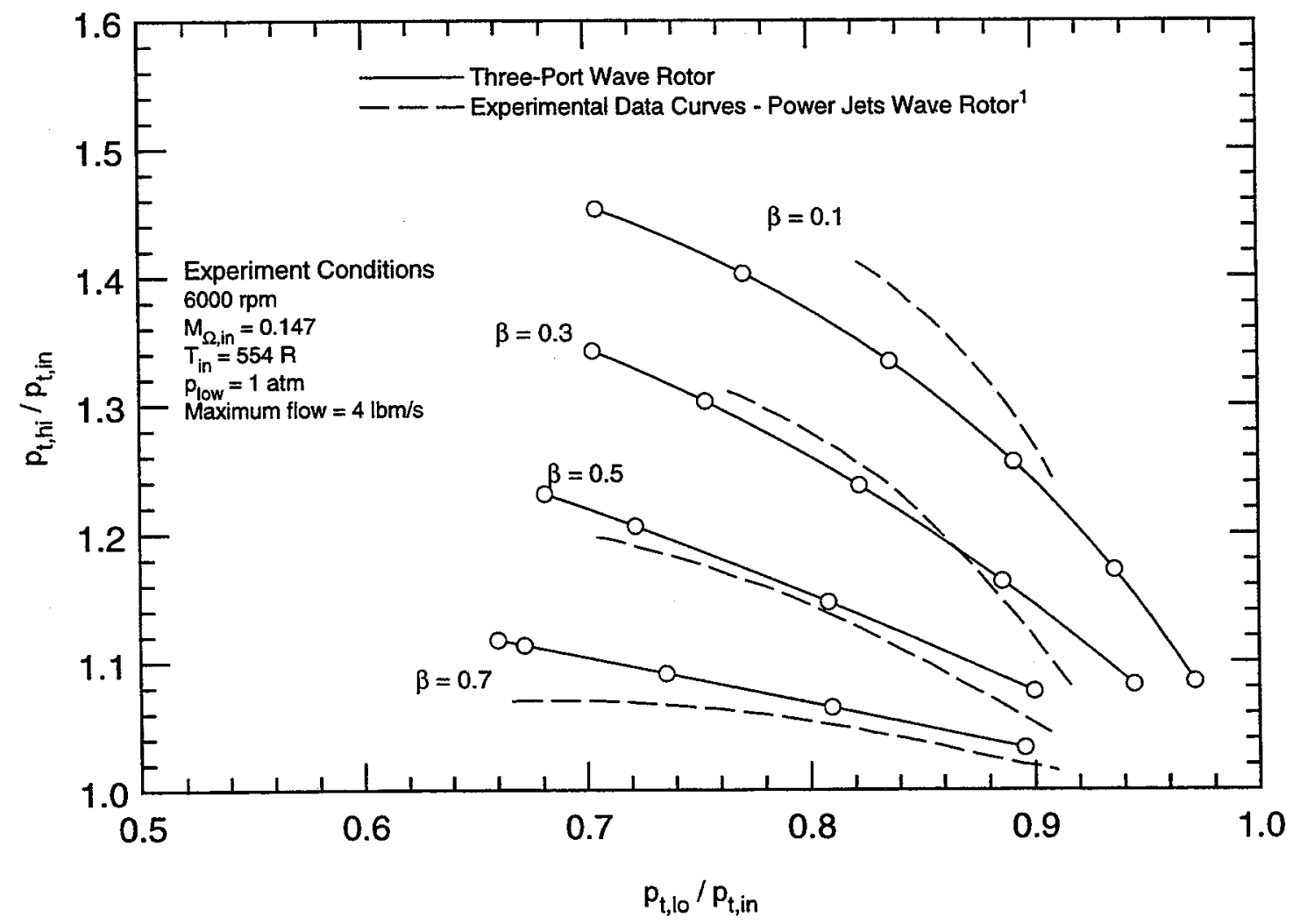

Figure 7. Comparison of three-port wave rotor performance curves predicted by present model and from experiment. ${ }^{1}$ 


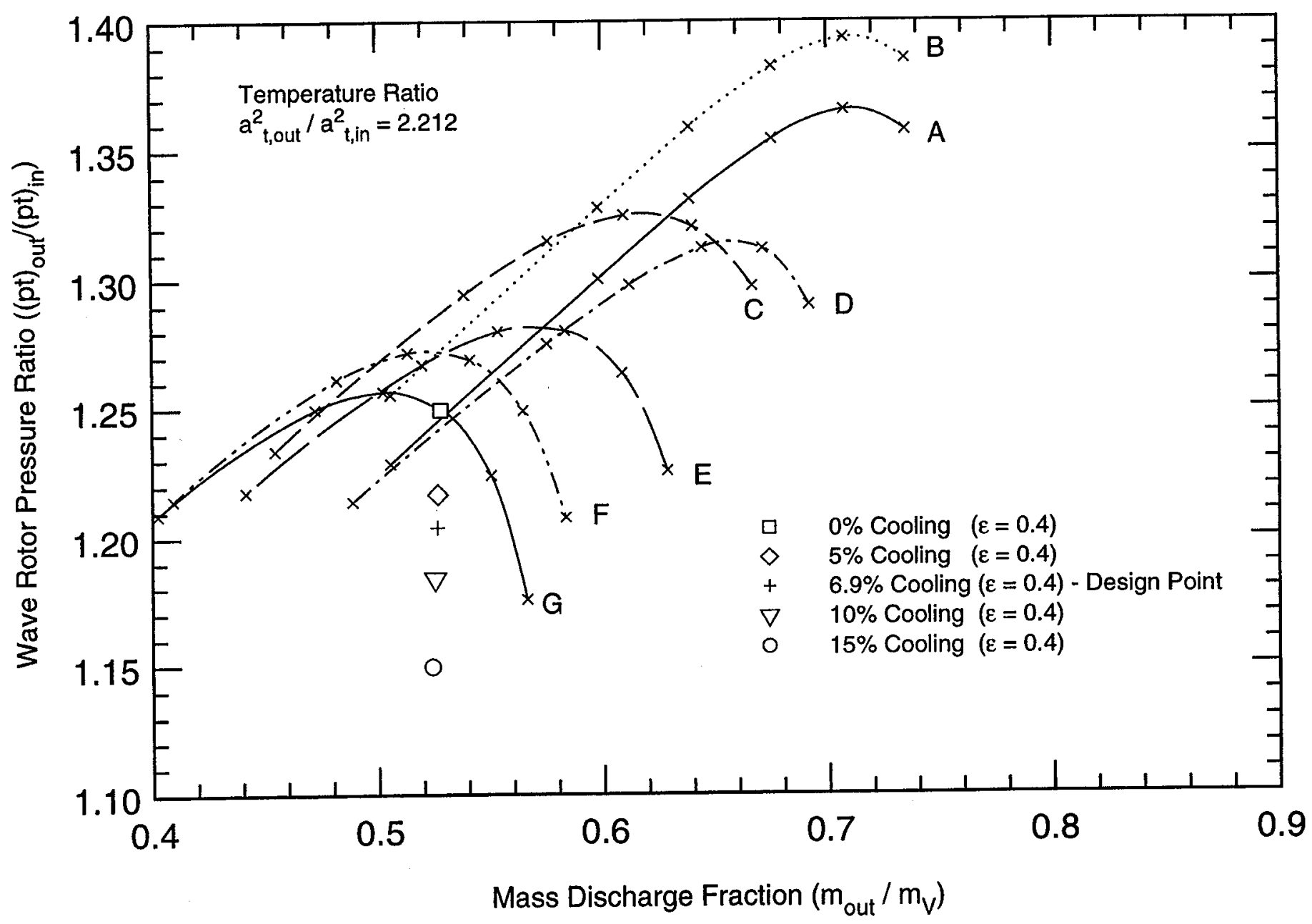

$A-M_{\Omega}=0.25 ; \tau_{V}=0.0 ; \mu=0 ;$ Blockage $=0.00 ; R_{H} / R_{T}=1.0 \quad E-M_{\Omega}=0.25 ; \tau_{V}=0.4 ; \mu \neq 0 ;$ Blockage $=0.00 ; R_{H} / R_{T}=1.0$ $B^{*}-M_{\Omega}=0.25 ; \tau_{v}=0.0 ; \mu=0 ;$ Blockage $=0.00 ; R_{H} / R_{T}=1.0 \quad F-M_{\Omega}=0.25 ; \tau_{V}=0.4 ; \mu \neq 0 ;$ Blockage $=0.08 ; R_{H} / R_{T}=1.0$ C $-M_{\Omega}=0.25 ; \tau_{V}=0.4 ; \mu=0 ;$ Blockage $=0.00 ; R_{H} / R_{T}=1.0 \quad G-M_{\Omega}=0.25 ; \tau_{V}=0.4 ; \mu \neq 0 ;$ Blockage $=0.08 ; R_{H} / R_{T}=2 / 3$. D $-M_{\Omega}=0.25 ; \tau_{\mathrm{V}}=0.0 ; \mu \neq 0 ;$ Blockage $=0.00 ; R_{H^{\prime}} / R_{T}=1.0 \quad(*=$ Relative Frame Pressure Ratio $)$

Figure 8. Wave rotor pressure ratio as a function of mass discharge fraction showing the effect of loss mechanisms. 


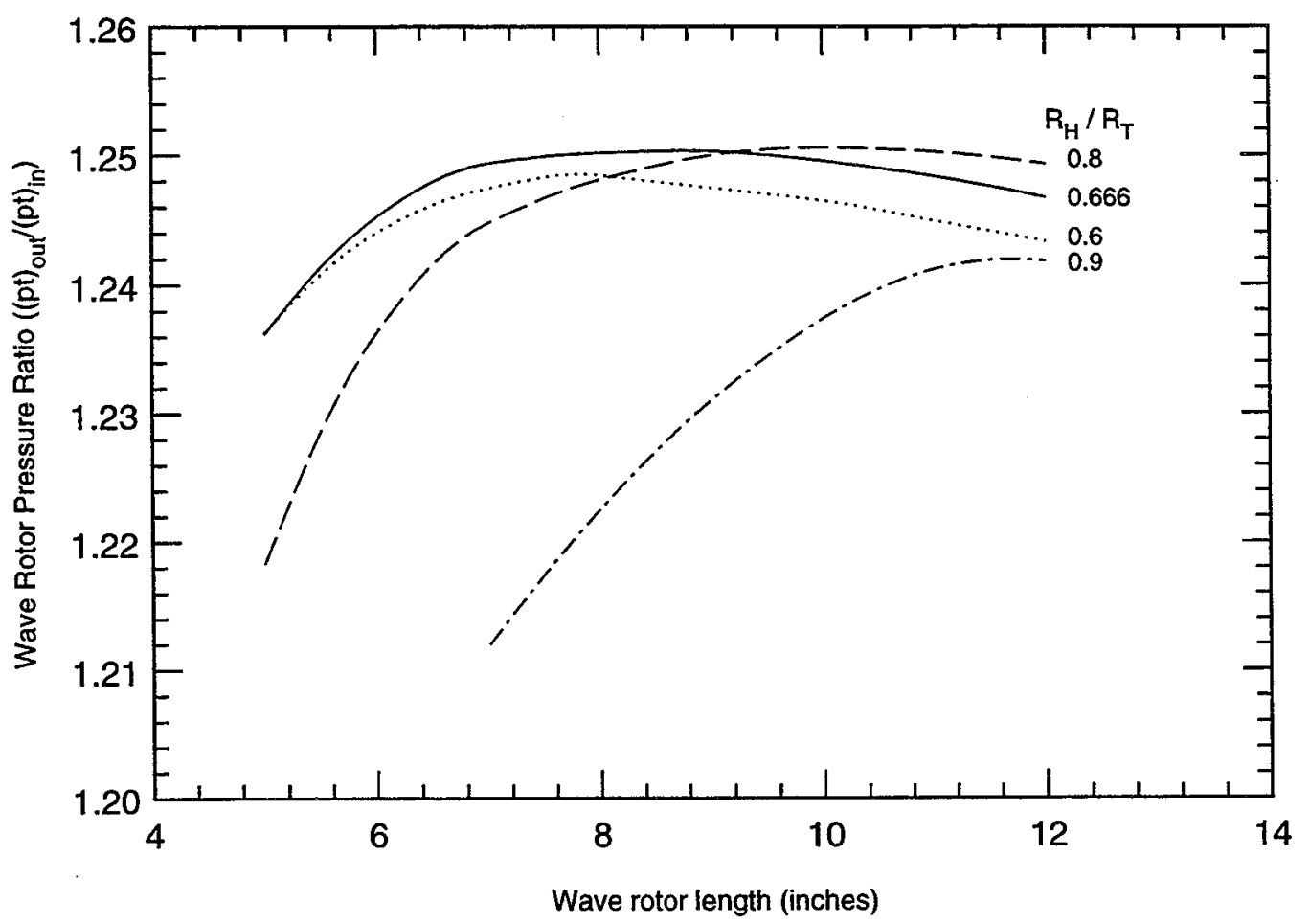

Figure 9. Wave rotor pressure ratio as a function of rotor length and hub-to-tip ratio for a $5 \mathrm{lb}_{\mathrm{m}} / \mathrm{s}$ machine.

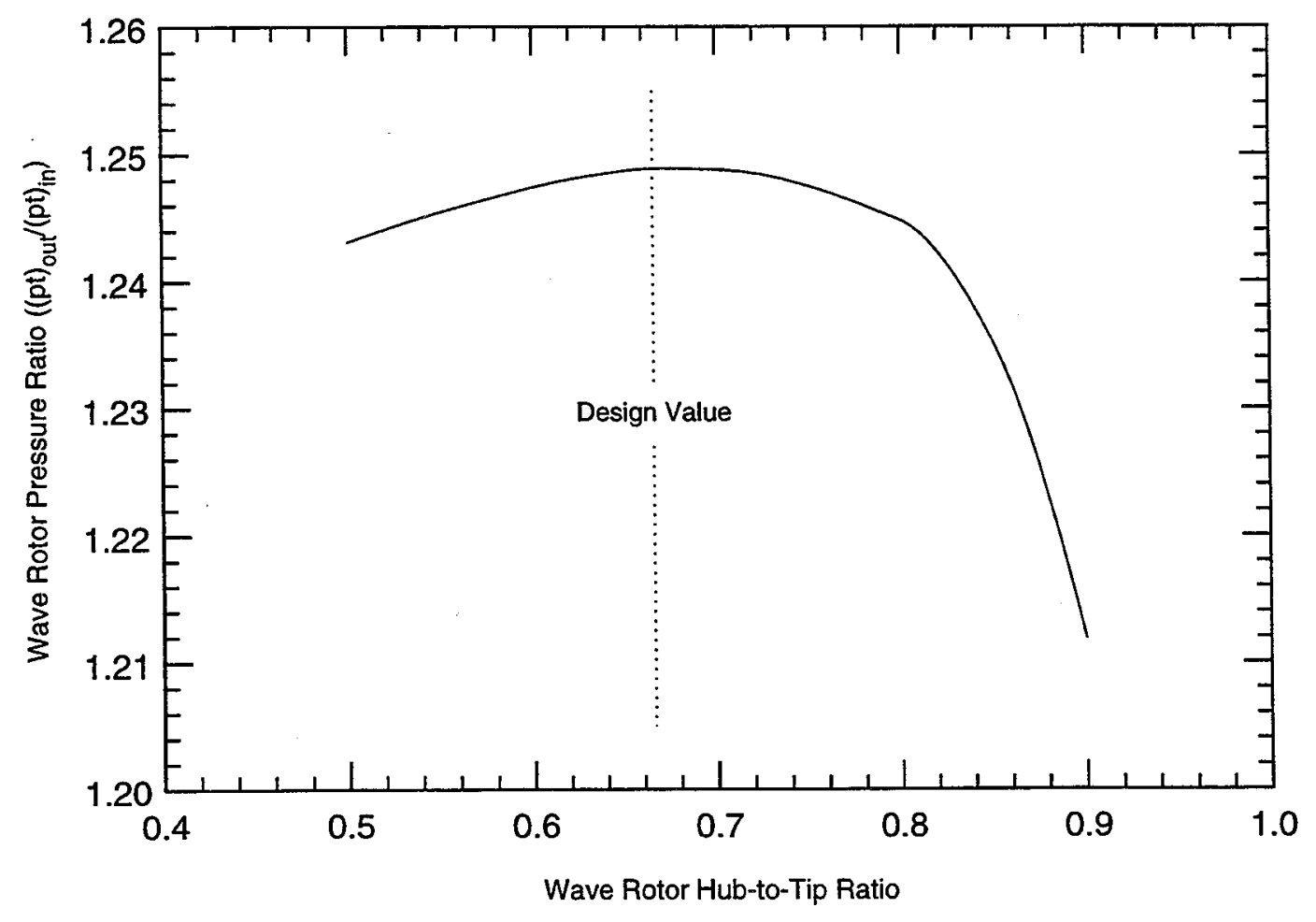

Figure 10. Wave rotor pressure ratio as a function of hub-to-tip ratio at a 7 inch rotor length. 

Public reporting burden for this collection of information is estimated to average 1 hour per response, including the time for reviewing instructions, searching existing data sources, gathering and maintaining the dala needed, and corpleting and reviowing the colloction of information. Send comments regarding this burden estimate or any other aspect of this Davis Highway, Suite 1204, Arlington, VA 22202-4302, and to the Office of Management and Budget, Paperwork Reduction Project (0704-0188), Washington, DC 20503.

\begin{tabular}{|l|c|c|}
\hline 1. AGENCY USE ONLY (Leave blank) & $\begin{array}{c}\text { 2. REPORT DATE } \\
\text { January } 1996\end{array}$ & $\begin{array}{r}\text { 3. AEPORT TYPE AND DATES COVERED } \\
\text { Technical Memorandum }\end{array}$
\end{tabular}

\section{TITLE AND SUBTTLE}

Macrosopic Balance Model for Wave Rotors

Gerard E. Welch
7. PERFoRMING ORGANIZATION NAME(S) AND ADDRESS(ES)

NASA Lewis Research Center

Cleveland, Ohio 44135-3191

and

Vehicle Propulsion Directorate

U.S. Amy Research Laboratory

Cleveland, Ohio 44135-3191

9. SPONSORING/MONITORING AGENCY NAME(S) AND ADDRESS(ES)

National Aeronautics and Space Administration

Washington, D.C. 20546-0001

and

U.S. Ammy Research Laboratory

Adelphi, Maryland 20783-1145
WU-505-62-75

1L161102AH45
5. FUNDING NUMBERS

8. PERFORMING ORGANIZATION REPORT NUMBER

E-10022

10. SPONSORING/MONITORING AGENCY REPORT NUMBER

NASA TM-107114

ARL-TR-925

AIAA-96-0243

11. SUPPLEMENTARY NOTES

Responsible person, Gerard E. Welch, organization code 2760, (216) 433-8003.

12a. DISTRIBUTIONAVAILABILITY STATEMENT

12b. DISTRIBUTION CODE

Unclassified -Unlimited

Subject Category 07

This publication is available from the NASA Center for Aerospace Information, (301) 621-0390.

13. ABSTRACT (Maximum 200 words)

A mathematical model for multi-port wave rotors is described. The wave processes that effect energy exchange within the rotor passage are modeled using one-dimensional gas dynamics. Macroscopic mass and energy balances relate volume-averaged thermodynamic properties in the rotor passage control volume to the mass, momentum, and energy fluxes at the ports. Loss models account for entropy production in boundary layers and in separating flows caused by blade-blockage, incidence, and gradual opening and closing of rotor passages. The mathematical model provides a basis for predicting design-point wave rotor performance, port timing, and machine size. Model predictions are evaluated through comparisons with CFD calculations and three-port wave rotor experimental data. A four-port wave rotor design example is provided to demonstrate model applicability. The modeling approach is amenable to wave rotor optimization studies and rapid assessment of the trade-offs associated with integrating wave rotors into gas turbine engine systems.

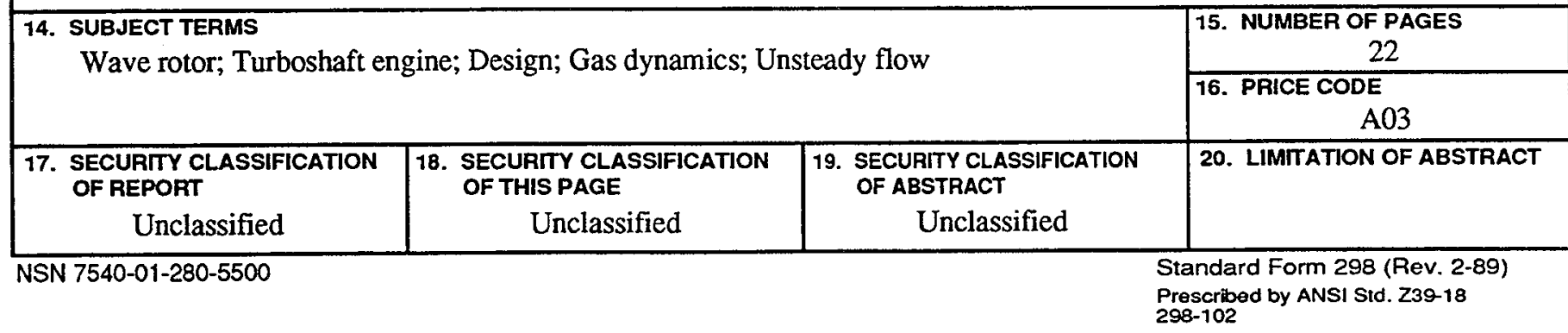


National Aeronautics and

Space Administration

Lewis Research Center 21000 Brookpark Rd.

Cleveland, $\mathrm{OH}$ 44135-3191

Official Business

Penalty for Private Use $\$ 300$

POSTMASTER: If Undeliverable — Do Not Return 